\title{
Poly(amidoamine) Hydrogels as Scaffolds for Cell Culturing and Conduits for Peripheral Nerve Regeneration
}

\author{
Fabio Fenili, Amedea Manfredi, Elisabetta Ranucci, and Paolo Ferruti \\ Department of Industrial and Organic Chemistry, The University of Milan, Via Venezian 21, 20133 Milan, Italy \\ Correspondence should be addressed to Paolo Ferruti, paolo.ferruti@unimi.it
}

Received 6 June 2011; Revised 27 July 2011; Accepted 27 July 2011

Academic Editor: Shanfeng Wang

Copyright () 2011 Fabio Fenili et al. This is an open access article distributed under the Creative Commons Attribution License, which permits unrestricted use, distribution, and reproduction in any medium, provided the original work is properly cited.

Biodegradable and biocompatible poly(amidoamine)-(PAA-) based hydrogels have been considered for different tissue engineering applications. First-generation AGMA1 hydrogels, amphoteric but prevailing cationic hydrogels containing carboxylic and guanidine groups as side substituents, show satisfactory results in terms of adhesion and proliferation properties towards different cell lines. Unfortunately, these hydrogels are very swellable materials, breakable on handling, and have been found inadequate for other applications. To overcome this problem, second-generation AGMA1 hydrogels have been prepared adopting a new synthetic method. These new hydrogels exhibit good biological properties in vitro with satisfactory mechanical characteristics. They are obtained in different forms and shapes and successfully tested in vivo for the regeneration of peripheral nerves. This paper reports on our recent efforts in the use of first-and second-generation PAA hydrogels as substrates for cell culturing and tubular scaffold for peripheral nerve regeneration.

\section{Introduction}

Tissue loss or end-stage organ failure caused by injury or other types of damage is one of the most devastating and costly problems in human health care. Surgical strategies that have been developed to address these problems include organ transplantation from one individual to another, tissue transfer from a healthy site to the diseased site in the same individual, and replacement by using mechanical devices such as joint prosthesis or dialysis machine. Moreover, medical treatment encompassed supplementation of metabolic products of the nonfunctional tissue. Though significant advances have been achieved in terms of health care by these therapeutic options, many limitations and unsolved issues remain [1]. The number of organs available for transplantation is far exceeded by the number of patients needing such procedures. In Europe in 2010 alone, approximately 9,300 people were on the waiting list for an organ transplant due to end-stage organ failure, but only 3,100 transplants were performed [2]. Tissue transfer cannot replace all the functions of the original tissue and bears the risk of donorsite complications.
Tissue engineering "is an interdisciplinary field that applies the principles of engineering and of life science towards the development of biological substitutes that restore, maintain or improve tissue or organ function." This definition is based on several articles, by Langer and Vacanti, that were published in the 1990s [3-6]. In those articles tissue engineering is proposed as an alternative to organ transplantation when all the other treatments fail using three main strategies. The first, the utilization of isolated cells, which has the great advantage to replace just the cells that are really needed and to eventually genetically manipulate them before infusion. This strategy allows for minimal invasive surgery, but there is always the possibility of immunological rejection or failure in maintaining new functions. The second approach is that of using tissueinducing substances such as growth factors or cytokines. However, drawbacks of this solution are purification and large-scale production issues, and it is always necessary to have a system to deliver the bioactive molecule to its target. Finally, the third strategy utilizes cells placed on a scaffold that serve as a synthetic extracellular matrix to organize cells into a three-dimensional architecture and to present stimuli 


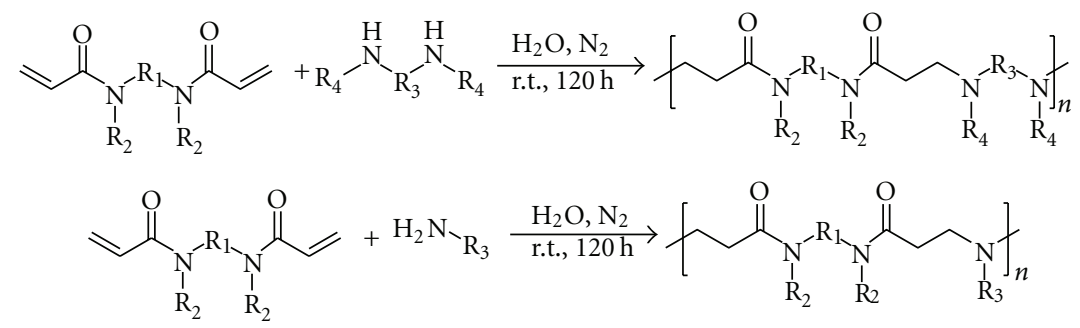

Scheme 1: Synthesis of linear PAAs. $\mathrm{R}_{1}, \mathrm{R}_{2}, \mathrm{R}_{3}$, and $\mathrm{R}_{4}$ can be any alkyl residues eventually containing carboxyl, amide, ester, and ether groups.

TABLE 1: Acid-base properties of the same PAA polymers.

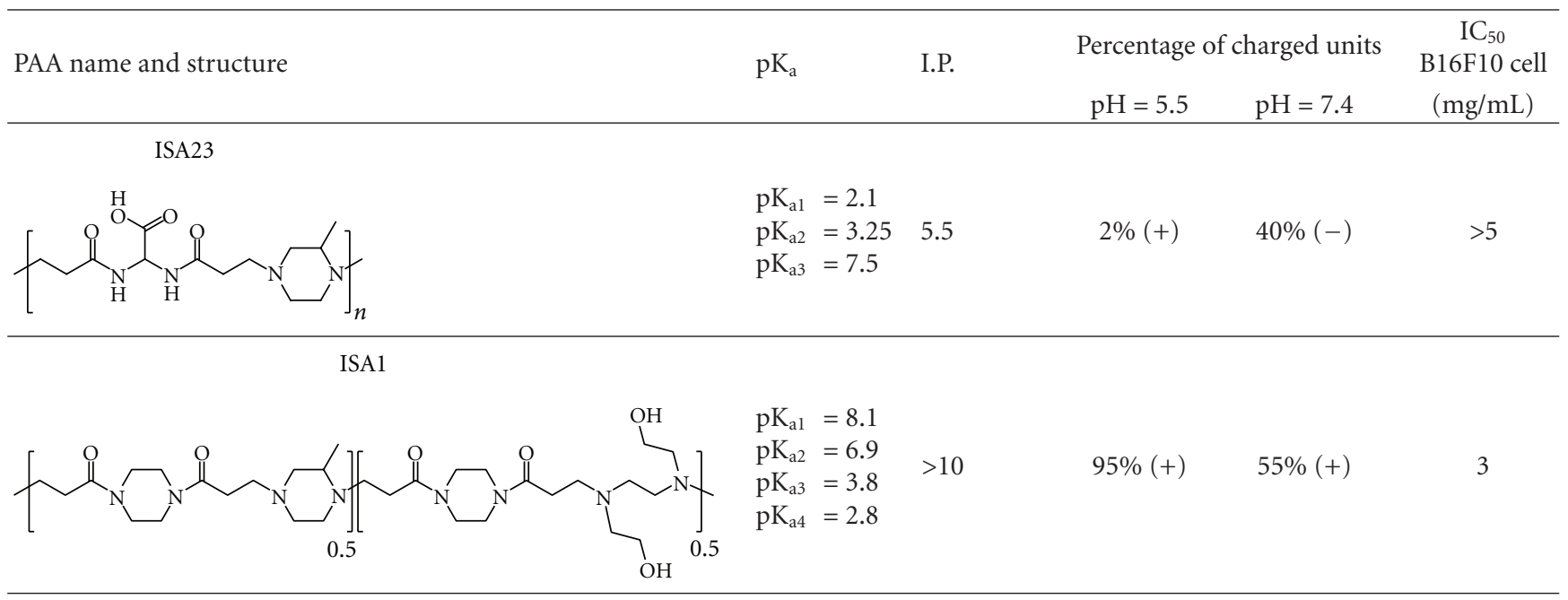

which direct the growth and formation of a desired tissue [7]. This strategy is currently used in tissue engineering.

Scaffolds can be produced from natural materials or synthetic polymers. In general, the ideal scaffold should be three dimensional, highly porous with an interconnected pore network, and biocompatible with a controlled degradation rate, should have an appropriate surface for cell adhesion, proliferation, and differentiation, and should maintain proper mechanical properties. Among all the synthetic polymeric materials that have been found to be suitable for tissue engineering applications, special attention has been recently given to biodegradable polymers and hydrogels. Several reviews in literature the describe the use of natural [8-15] and synthetic [16-20] biodegradable polymers as well as some nonbiodegradable $[21,22]$ ones, which are currently used for cartilage, nerve repair, bone, cardiac, vascular graft, and many other tissue engineering applications. Among synthetic materials, increasing attention has been paid to hydrogels due to their tissue-like properties for interaction with living cells, such as similar water content and permeability to oxygen and metabolites [23]. Synthetic hydrogels, as opposed to naturally derived materials, are more advantageous, giving the possibility of a complete control over hydrogel composition, surface properties, and other key parameters such as water absorption and (bio)degradation time. Moreover, hydrogel structures could be used to encapsulate cells, pro- teins, and signaling factors, as well as bioactive moieties to be slowly released during cell growth [24]. This paper reports on our recent efforts in the use of first-and second-generation poly(amidoamine) hydrogels as substrates for cell culturing and tubular scaffold for peripheral nerve regeneration.

\section{Poly(amidoamine) Hydrogels: Synthesis and Properties}

PAAs are a family of synthetic polymers containing tertiary amino and amido groups regularly arranged along their polymer chain $[25,26]$. They are obtained by Michaeltype polyaddition of primary or secondary amines to bisacrylamides (Scheme 1).

PAAs are extremely versatile materials. PAAs containing as side substituents other chemical functions, such as additional tertiary amino groups, carboxyl groups, hydroxyl groups, and allyl groups, can be easily obtained by using suitably functionalized monomers, as for instance aminocarbohydrate derivatives [27]. Peptides and proteins can also participate in the polyaddition reaction through their terminal amino groups as well as $\mathcal{E}$-lysine amino groups, if present [26-28]. Many PAAs exhibit a combination of properties imparting them a considerable potential in the biomedical field (see Table 1). They are highly hydrophilic and usually degrade in aqueous media at a rate 


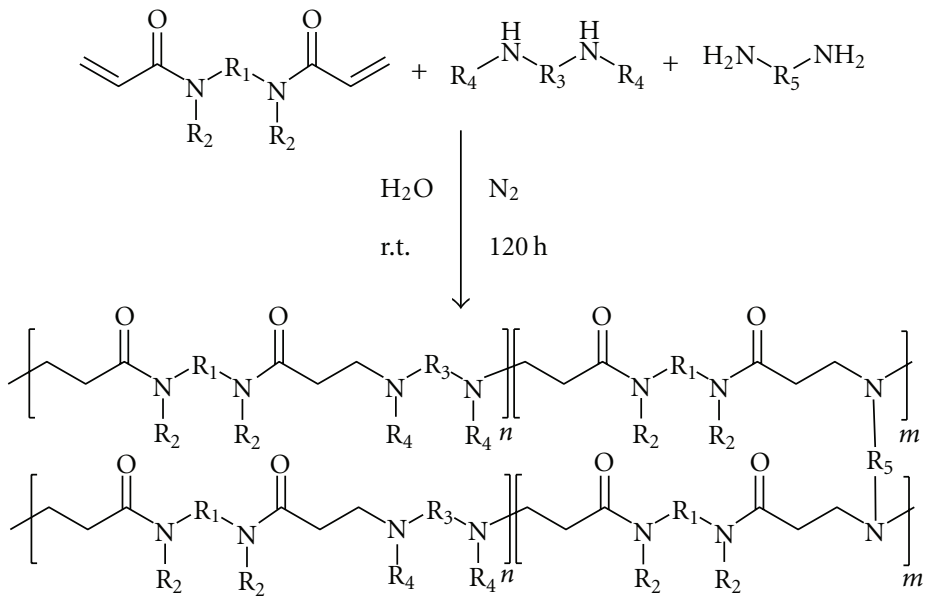

Scheme 2: General synthesis of PAA-based hydrogels.

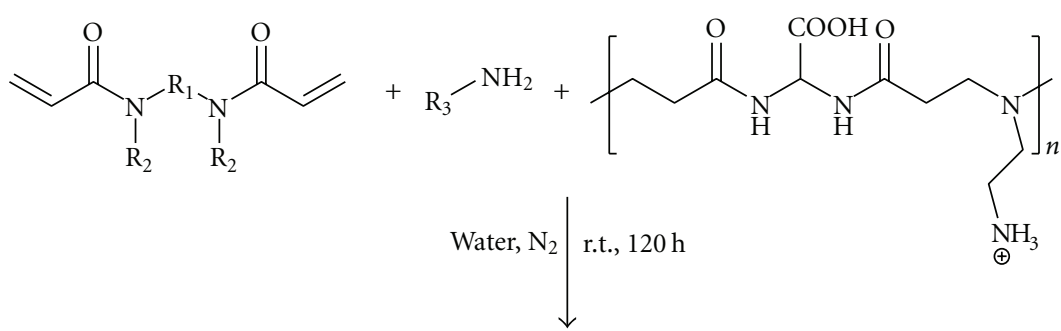

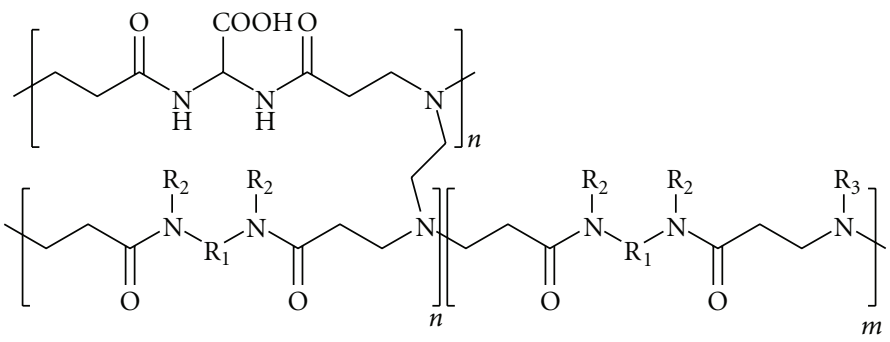

Scheme 3: Synthesis of PAA hydrogels using $\mathrm{NH}_{2}-\mathrm{BAC}$.

depending on their structure [29]. Moreover, many of them are almost nontoxic, in spite of their polycationic nature, with $\mathrm{IC}_{50}$ values ranging from 0.5 to $3.0 \mathrm{mg} / \mathrm{mL}[30,31]$. Amphoteric PAAs, that is, PAAs carrying carboxyl groups as side substituents, are even less toxic and may be approximately as biocompatible as dextran [32].

Crosslinked PAAs can be easily obtained by different methods. So far, the most often employed method is to introduce primary diamines as crosslinking agents into the polymerization mixture [33]. Primary diamines carry four different mobile hydrogens and hence behave as tetrafunctional monomers in PAA synthesis (Scheme 2). Crosslinked PAAs are typical hydrogels, absorbing large amounts of water if their crosslinking degree is not too high.

Another synthetic procedure leading to PAA-hydrogels involves the preparation of a linear PAA carrying primary amino pendants, such as the amphoteric one $\left(\mathrm{NH}_{2}-\mathrm{BAC}\right)$ prepared by polyaddition of monoprotonated EDA to BAC
(Scheme 3) [34]. This PAA can be used as multifunctional crosslinking agent in the place of diamines [35].

Amphoteric PAAs, whose polymer chain contains amide, amine, and carboxylate groups in regular sequence, can be considered in a sense protein-like synthetic materials. In fact, they exhibit good compatibility with proteins, as for instance albumin. It has also been demonstrated that different molecules and biomolecules, as oligopeptides and proteins [36], are capable of reproducing the receptorial sites of proteins playing a fundamental role in cell adhesion, such as fibronectin, laminin, and vitronectin [37]. Among these, the tripeptide RGD is presently the most popular [38].

Recently a peptidomimetic PAA, labeled AGMA1, has been obtained by polyaddition reaction of 2,2-bis(acrylamido)acetic acid and agmatine (4-aminobutyl guanidine) [39-41]. As reported in Figure 1, AGMA1 carries guanidine and carboxyl groups and shows a strong structural resemblance to the RGD sequence. 


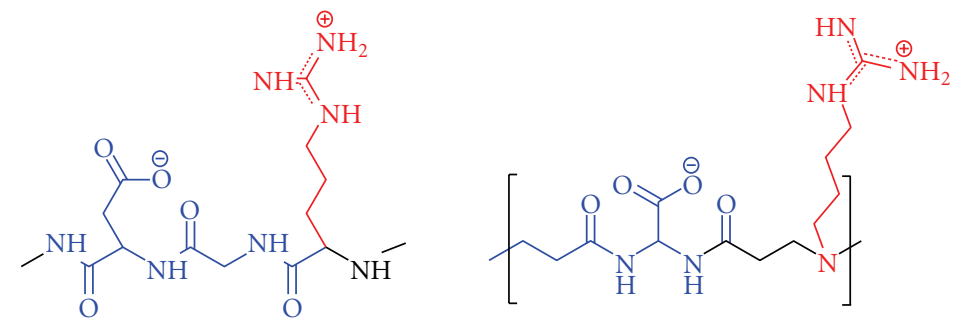

FIGURE 1: Structure of agmatine containing amphoteric poly(amidoamine) (right part) compared to the RGD tripeptide sequence.

TABLE 2: Acid-base properties of AGMA1.

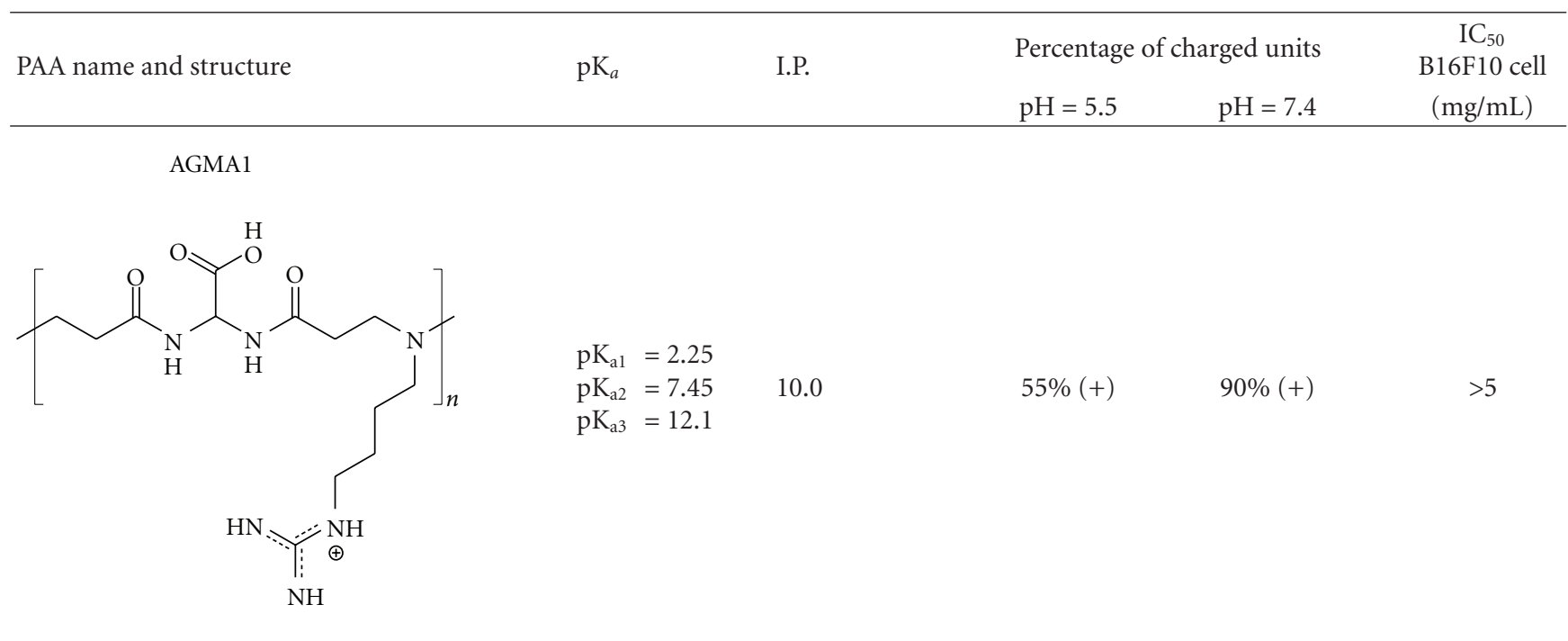

Agmatine-containing PAAs hydrogels, easily obtained using 4-aminobutyl guanidine as amine monomer, are fully cytocompatible and also show remarkable adhesion and proliferation properties towards several cell lines [42].

Agmatine contains a primary amino group and a guanidine group carrying five potentially mobile hydrogens that might participate in the polyaddition reaction. It is, therefore, a potential cross-linking agent in PAA synthesis like primary diamines as EDA. Nevertheless, a large difference in basic properties exists between the amine and the guanidine groups of agmatine. The latter has $\mathrm{pK}_{\mathrm{a}}>12$, much higher than that of any aliphatic amine, and remains protonated under the conditions employed in PAA synthesis (Table 2).

Degradation tests carried out on selected PAA hydrogels under conditions mimicking the body fluids $(\mathrm{pH} 7.4$ and $37^{\circ} \mathrm{C}$ ) reveal that their degradation products are completely nontoxic [42]. The mechanism of PAAs degradation seems to be purely hydrolytic as no vinyl groups, such as those that would be derived from a $\beta$-elimination reaction, can be determined. Furthermore, degradation seems not to be affected by the presence of isolated lysosomal enzymes at $\mathrm{pH}$ $5.5[43,44]$.

\section{Poly(amidoamine) Hydrogels as Substrates for Cell Culturing}

In the last few years the progress of biological sciences has led to outstanding developments in the field of cell culturing in vitro. Several new techniques, such as cell microarray or cells on chips, require reliable support materials with good biocompatibility and cell adhesion, preferentially disposable and simple to use $[45,46]$. Traditionally, cells culturing has been performed on two-dimensional substrates or on the surface of tissue analogs. Currently, various polymerbased materials, that is, polystyrene (PS), polycarbonate (PC), and polypropylene (PP), are applied as common bulk materials in two-dimensional cell culture systems, such as cell culture dishes and cell culture membranes. Tissue culture polystyrene (TCPS) is the most common cell culture substrate due to its easy processability and optical transparency, but it still needs to be modified with poly(D-lysine) to ensure cell adhesion [47]. Among all the synthetic polymeric materials that have been found to be suitable substrates for cell culturing, special attention has been recently given to hydrogels. Hydrogels present unique tissue-like properties for interactions with living cells [23, 48], such as water 
content and permeability to oxygen and metabolites. In principle, fully synthetic hydrogels, as opposed to naturally derived media (e.g., gelatin, chitosan, etc.), should be more advantageous, coupling the aforementioned properties with the possibility of complete control over hydrogel composition, crosslinking, and swelling. Hydrogels can be produced with tailored shape and thickness, even in 3D structures, and their surface can be patterned with lithographic techniques $[49,50]$. Moreover, hydrogels can be fittingly functionalized with biomolecules for obtaining customized properties. Cell adhesion on fully synthetic hydrogels, however, is still an issue for many of these materials, such as PHEMA or crosslinked PEG derivatives [51]. A number of chemical and physical modifications have been proposed to overcome this problem, often relying on modification of the synthetic surface with biological or biomimetic moieties, as peptides or proteins [52] typically, arginine-glycine-aspartate (RGD). The process of cell adhesion to a substrate, both on the natural ECM and synthetic materials, is mediated by interactions between surface ligands and cell receptors, such as transmembrane integrins and proteoglycans [53]. The tripeptide RGD, present in several ECM proteins, has been the object of intensive research in the last years [54]. In fact, several studies have shown that this tripeptide, and some of its analogues, can interact with adhesion-regulating proteins of the integrin family and play a role in promoting cell adhesion and spreading, mimicking the effect of some ECM proteins, such as fibronectin or vitronectin [55-57]. The overall action mechanism is still not completely clear, but some studies have associated it to the conformation of the guanidine side group of arginine, and its distance and angle from the acidic pendant of aspartic acid [58, 59]. Modification of chemical structures in order to include an RGD or RGD-like group has been proposed for a number of applications where cells interaction is desired to enhance adhesion or recognition by cellular receptors $[60,61]$.

Different PAA hydrogels have been tested as substrates for cell culture. They have been prepared using different crosslinkers, such as EDA, 1,10-diaminododecane, or the linear $\mathrm{NH}_{2}-\mathrm{BAC}$ carrying primary amino pendants (Table 3 ).

Cytotoxicity tests have been carried out by the direct contact method with fibroblast cell lines on the hydrogels both in their native state (i.e., as free bases), and as salts with acids of different strength, namely, hydrochloric, sulfuric, acetic, and lactic acid. This has been done in order to ascertain if there is any counterion-specific influence on cytotoxicity. It has been found that all the amphoteric PAA hydrogels considered are cytobiocompatible both as free bases and salts (Figure 2), and their biological performance is independent of the counterion's nature [33] (Figure 3).

Degradation tests have been performed on selected hydrogels samples under controlled conditions simulating biological environments, that is, Dulbecco medium at $\mathrm{pH}$ 7.4 and $37^{\circ} \mathrm{C}$. All samples degrade completely and dissolve within 10 days. The degradation products of all samples have demonstrated to be noncytotoxic [33].

PAA-AG1 and PAA-AG2 are bioactive in terms of allowing cell adhesion and further proliferation. The morphology of cells grown onto the surfaces of both hydrogels is comparable with that of cells grown on TCPS used as control. In all cases, cell confluence has been reached after 10 days from the beginning of the experiments [42] (Figure 4).

Swelling tests have demonstrated that all PAA hydrogels have a high swelling capability. This property, not unexpected considering the hydrophilic and ionic nature of all investigated PAA hydrogels, ensures an efficient diffusion of low molecular weight substances, thus facilitating purification processes consisting in extensive extraction with water. However, the mechanical strength of the hydrogels in the swollen form is modest and the materials appear relatively fragile. The swelling of PAA hydrogels protonated with different acids is still very high, and not significantly different from that of the corresponding free bases, with the exception of the sulfates, which are slightly less swollen.

A systematic comparative study of the response of an epithelial cell line has been performed on AGMA1-EDA hydrogels, on nonfunctionalized amphoteric ISA23-EDA hydrogels, and tissue culture plastic substrates $[62,65]$. As previously pointed out, the AGMA1 repeating units (Figure 1) are very similar to the well-known adhesionmodulating RGD peptide sequence. Since ISA23 does not carry any guanidine pendant group, it is expected to show no significant cell adhesion properties [33] and is used as a nonfunctionalized control. In order to make the hydrogels more handy, a new bilayered system has been designed, prepared and tested. It is composed by a functionalized glass support covered with a thin hydrogel layer. MDCK cells have been plated on the two types of hydrogels and on TCPS. Within 1 hour after plating, no evident differences are observed between AGMA1-EDA and ISA23-EDA, and the amount of adhered cells on these substrates is significantly lower than on TCPS (Figure 5). After 3 hours, the trend is substantially different, and the adhesion on AGMA1-EDA is comparable to that on TCPS (within one standard deviation) whereas on ISA23-EDA remains definitely lower (Figure 5).

After 1-2 days, effective MDCK cells proliferation on TCPS is observed, whereas this process on AGMA1-EDA appears to be slowed down (Figure 6).

After 3 days, meanwhile the cells on TCPS achieve confluence, the cells on AGMA1-EDA form clusters and no confluence is observed as reported in Figure 7.

This effect may be explained considering that, despite the fact that PAA hydrogel layer are supported by a rigid material, cells probably experience a more compliant substrate than TCPS. Optical images indicate that the cells adhered on AGMA1-EDA are less spread with respect to TCPS. This behavior could be ascribed to the occurrence of opposite stimuli to the cells: the compliance of the hydrogel surface, which can prevent a strong cell-substratum interaction and stress fiber formation, and the presence of integrin ligands, which favors a more effective cell-substratum adhesion. The behavior of the actin stress fibers on the different substrates is shown in Figure 8. Slower actin stress fiber formation on AGMA1-EDA and ISA23-EDA matches the slower spreading on these hydrogels. Chemical properties can participate with physical characteristics of substrates to affect cell adhesion. It has been shown that the presentation of integrin ligands in a clusterized form enables the formation of focal contacts 
TABle 3: Partial structures of PAA hydrogels.

ISA23-EDA

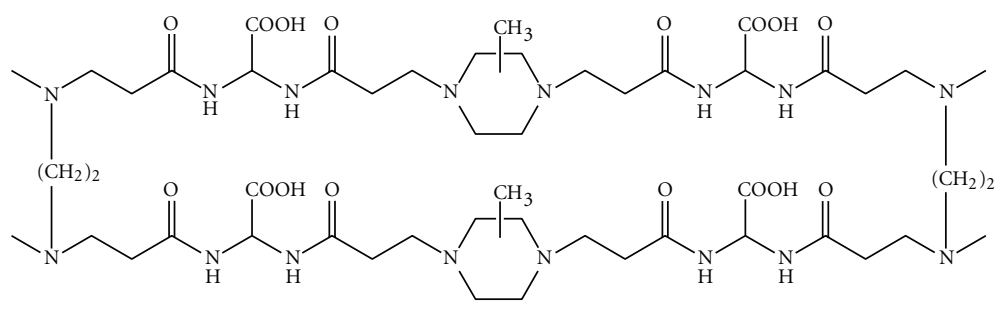

AGMA1-

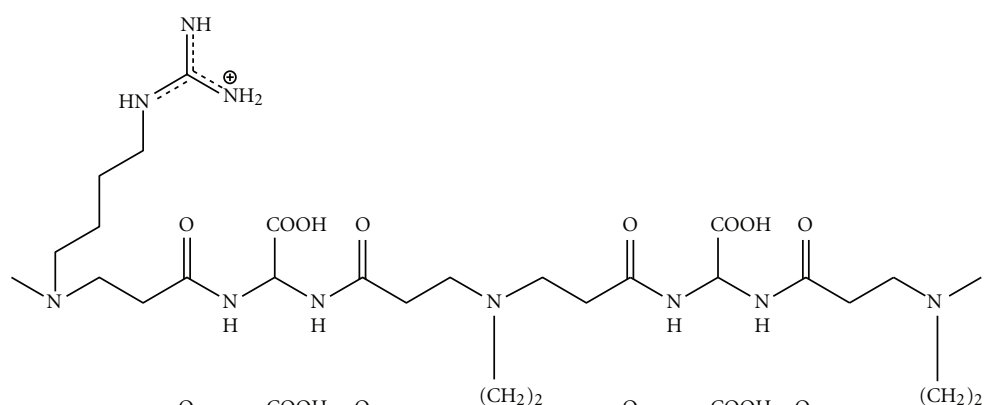

EDA

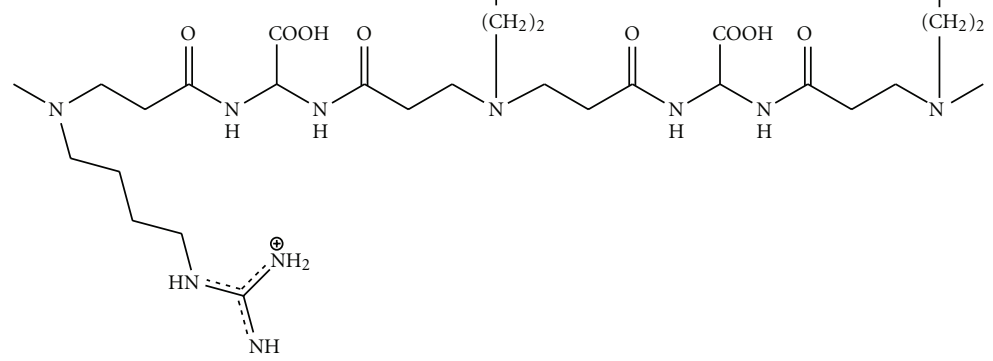

$[62,65$

PAA-DD<smiles></smiles>

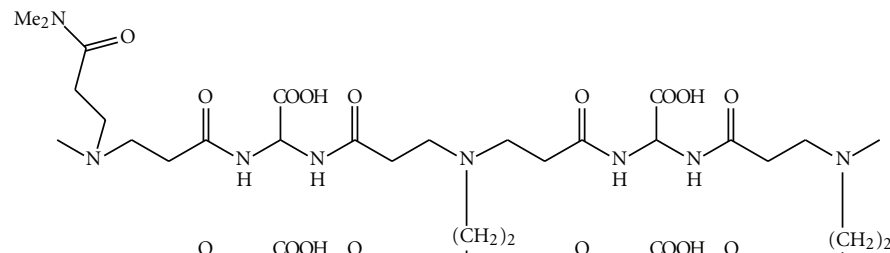

PAA-ED2<smiles>CCCCCCCCCCCCCC(=O)NC(NC(=O)CCN(C)C)C(=O)NC(NC(=O)CCN(C)CCC(N)=O)C(=O)O</smiles> 
International Journal of Polymer Science

7

Table 3: Continued.

Code

Structure

Reference

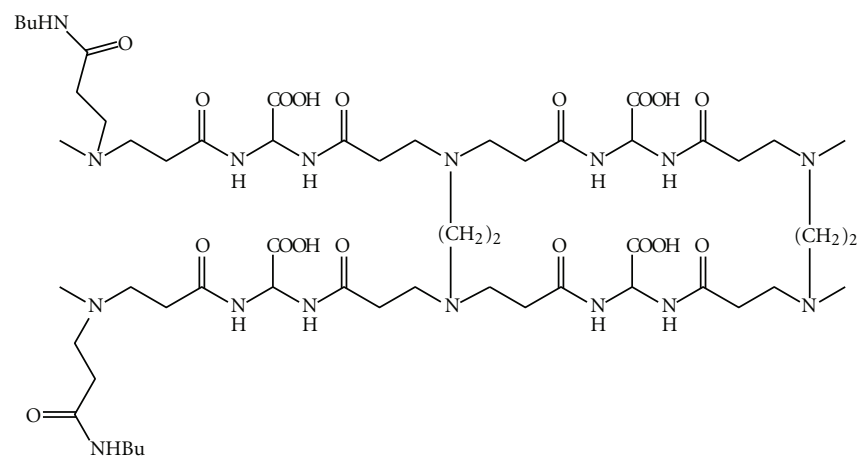

[33]

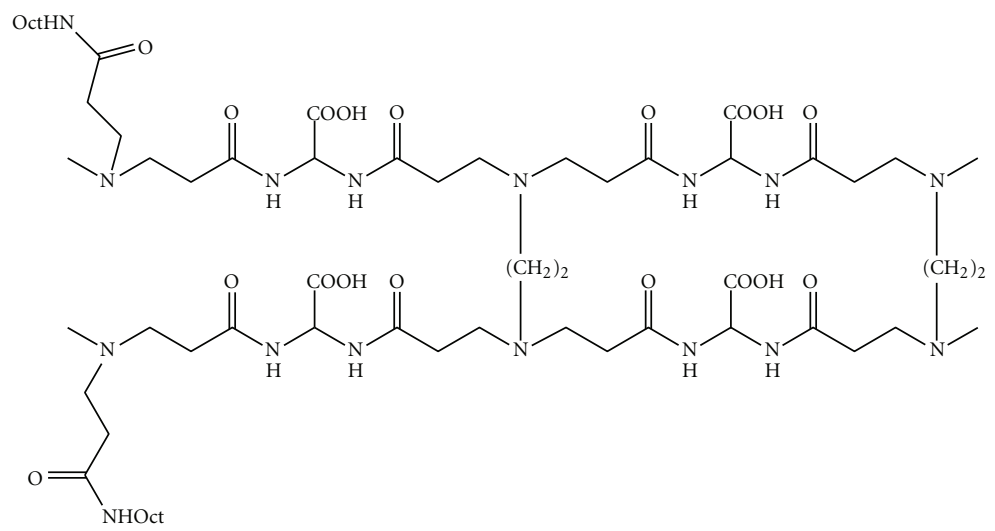

[33]<smiles>CCCNC(N)N</smiles>

$\overbrace{\mathrm{N}}^{\mathrm{CO}}$

PAA-AG1<smiles>CC1CN(CCC(=O)NC(NC(=O)CCN(C)CCCCCNC(=N)N)C(=O)O)CCN1CCC(=O)NC(NC(=O)CCN(C)C)C(=O)O</smiles>

[42] 
Table 3: Continued.

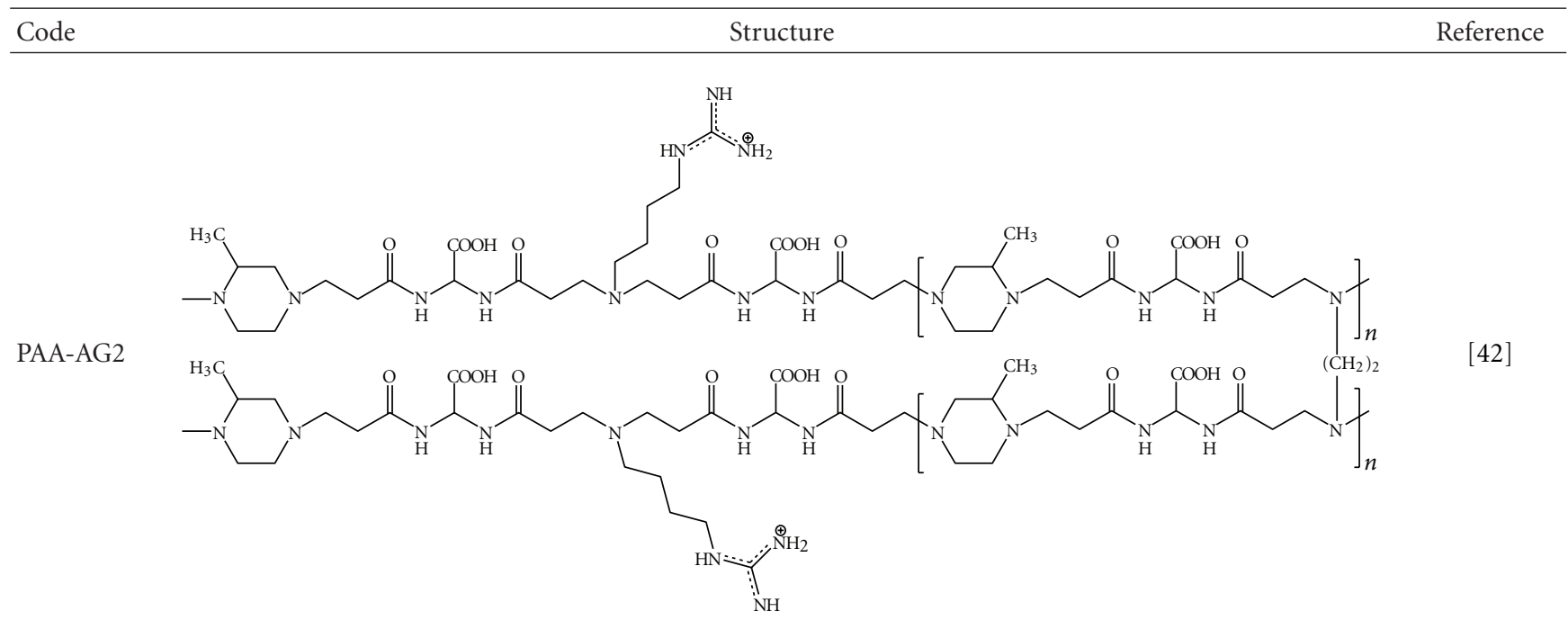

and stress fibers [66] and determines cell spreading [67]. A uniform low density of integrin ligands, instead, is unable to support stress fiber formation [66]. Therefore, slower spreading and stress fiber formation on AGMA1-EDA hydrogels could be also due to a more uniform (i.e. not clusterized) presentation of integrin ligands compared to the TCPS. It is also interesting to note that on ISA23-EDA cell islands often show membrane structures as filopodia and lamellipodia indicating not stable focal contacts and a tendency to cell migration [68].

\section{PAA Hydrogels for Microfluidics and Lab-on-Chip Applications}

Microfluidics deals with the precise control and manipulation of fluids that are geometrically constrained to a small, typically submillimeter, scale. It is a multidisciplinary field intersecting engineering, physics, chemistry, microtechnology, and biotechnology, with practical applications to the design of systems in which such small volumes of fluids will be used.

Microfluidics has emerged at the beginning of the 1980s and is used in the development of DNA chips, labon-chip technology, micropropulsion, and microthermal technologies [69-71].

In addition to functionalizing biomaterials with ECMderived cell adhesive molecules, there is emerging evidence indicating that the surface topography, stiffness, and electrical properties play an important role in cells adhesion and growth [72]. Based on these premises, ISA23-EDA hydrogels have been used for the preparation of patterned substrate using a scanning electron microscope. The method consists of exposing dry hydrogel films to electron beam (computer assisted) in high vacuum chamber [63]. Fluorescent labelled, FITC or TRITC, proteins such as BSA, the hormone EGF FITC, and the biomolecule Phalloidin-TRITC, attach selectively to an electron-beam-modified surface in a dose dependent manner. Higher exposure doses lead to a higher protein or biomolecules attachment. Cells lines, such as MDCK and PC12, have been plated on the patterned surface. MDCK cells growth is observed along all surfaces, independently of pattern or other physic, and chemical modifications. The PC12 cell line, able to differentiate into neural cells when induced by NGF, presents a strong preference for the electron-beam-modified substrate. A 24hours-PC12 cell culture, NGF non-treated, has been grown on the top of a hydrogel patterned with a chess-like area according to Figure 9 (total area $600 \times 600 \mu \mathrm{m}$ ). Containing alternate exposed and nonexposed squares $(100 \times 100 \mu \mathrm{m})$, $84 \%$ of the total cells ( 400 cells) are in the electron-beamexposed squares (Figure 9) [63].

By exploiting the selective attachment growth and differentiation of PC12 cells on microwells connected by thin channels, we have fabricated a neural network of single cells connected by neurites extending along the microchannels [63]. The fine control of this neural network is further strengthened by the fact that the number of outcoming neurites is determined by the number of microchannels originating from each microwell (Figure 10).

E-beam lithography on PAA hydrogels opens up the opportunity of producing multifunctional microfluidics devices supported on a small glass chip and incorporating complex topographies, allowing precise control of the growth and organization of individual cells and providing the capability to study physiologic and pharmacologic responses at a single cell level.

\section{PAA Hydrogels as Scaffolds for Peripheral Nerve Regeneration}

Peripheral nerve injuries present a significant clinical challenge across the world [73]. Injuries to the peripheral 


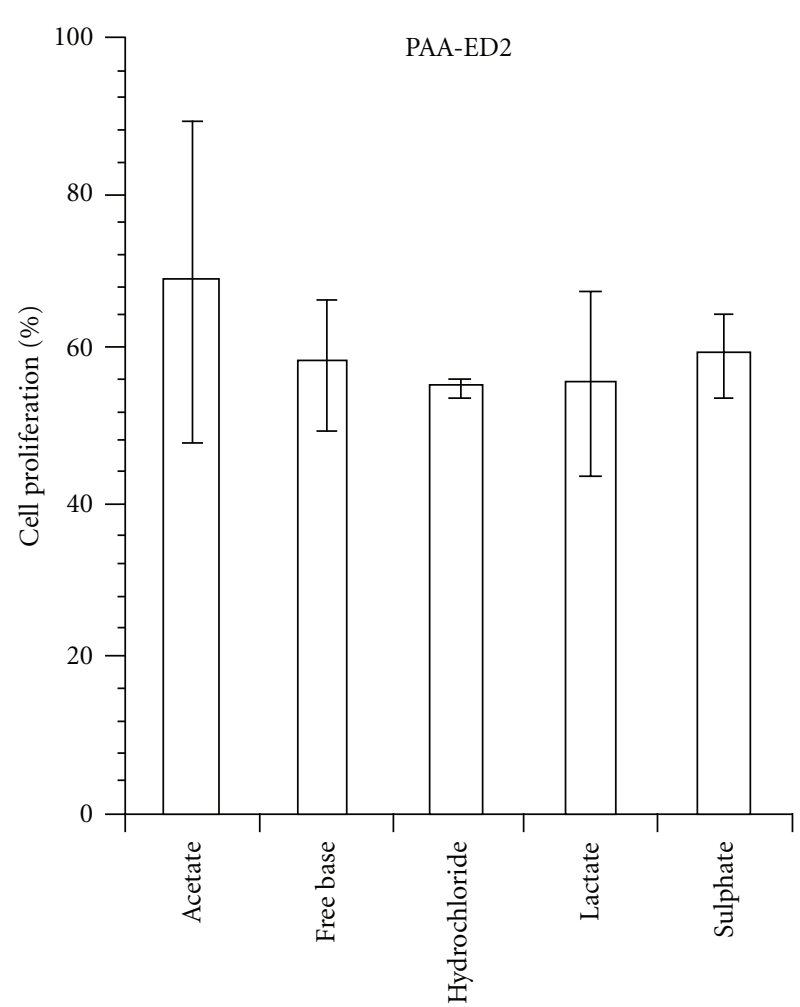

(a)

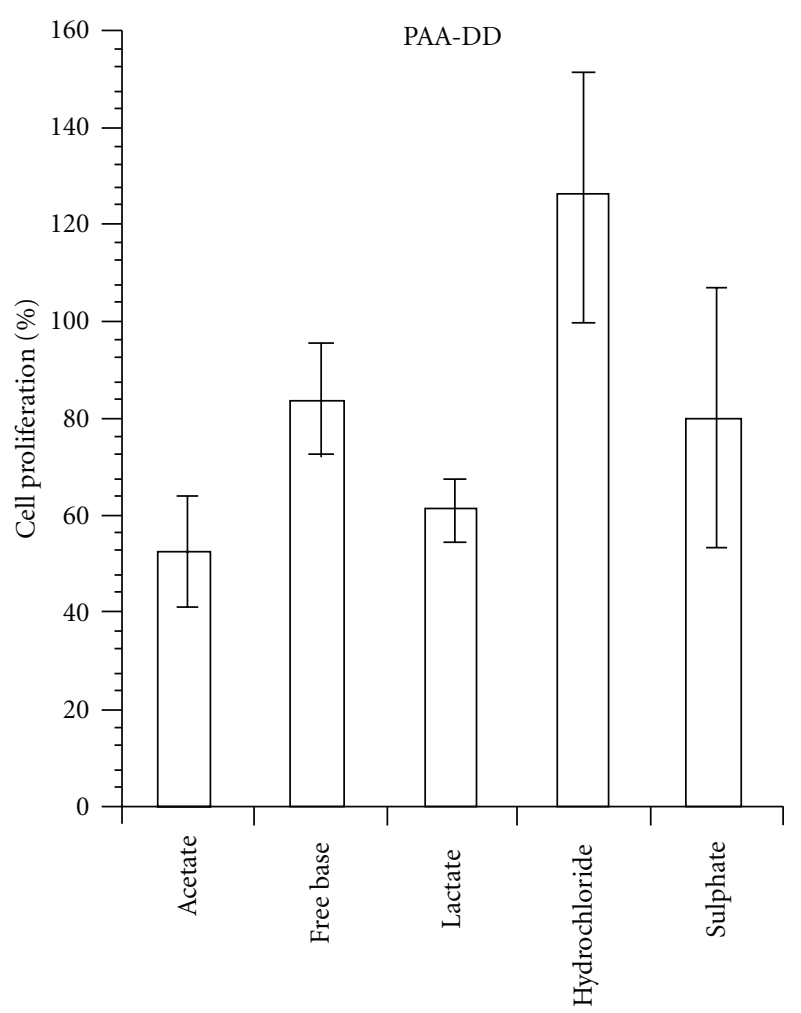

(b)

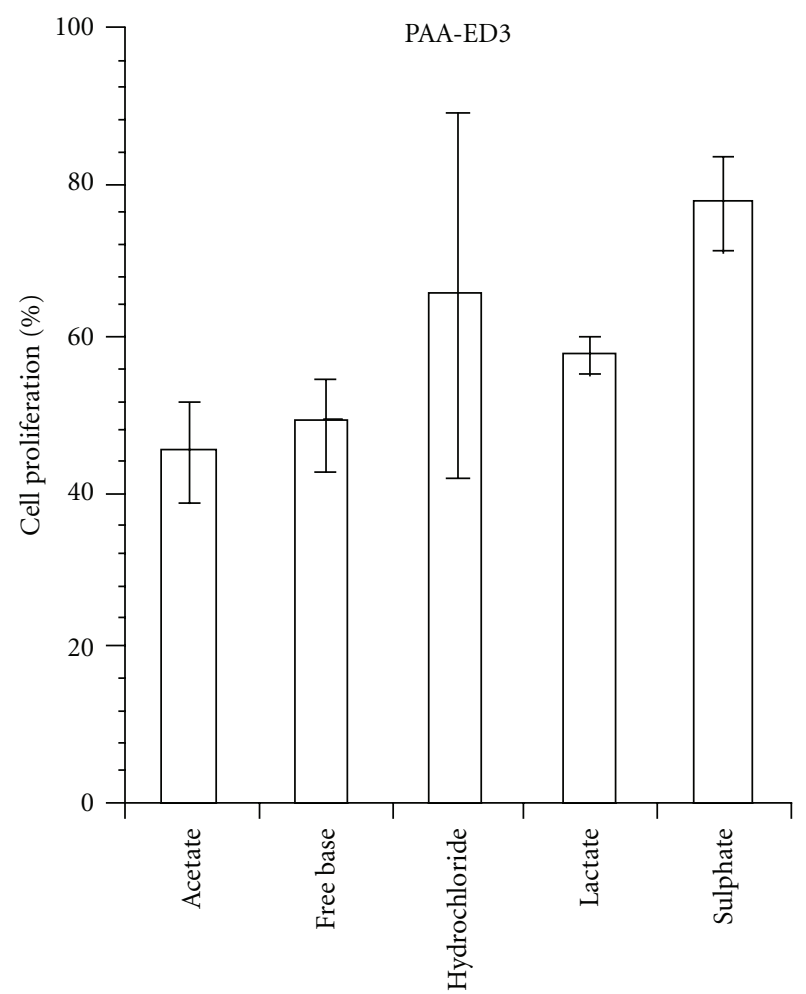

(c)

FIgURe 2: Results of the cytotoxicity tests of PAA-ED2, PAA-DD and PAA-ED3 hydrogels, as free base and ammonium salts, carried out on fibroblast cells by means of the direct contact method [33]. 


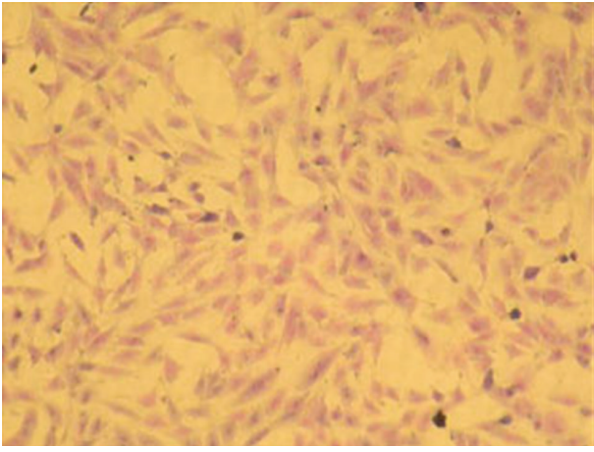

Figure 3: Morphology of mouse embryo fibroblasts in the cell proliferation experiment carried out by the direct contact method in the presence of PAA-DD as lactate ammonium salt [33].

PAA-AG2

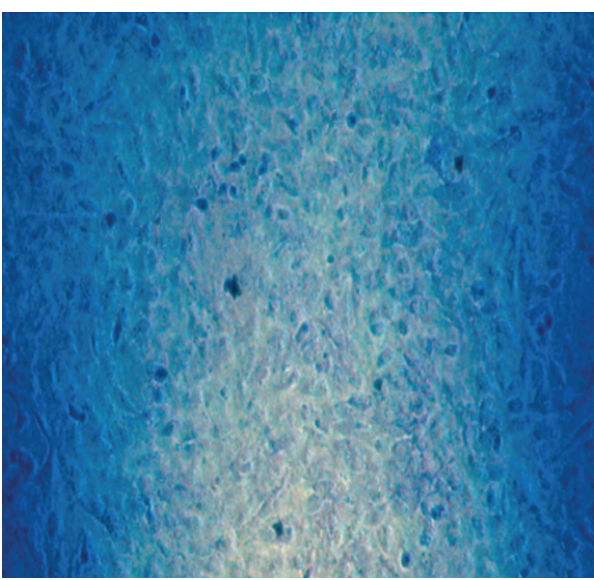

(a)

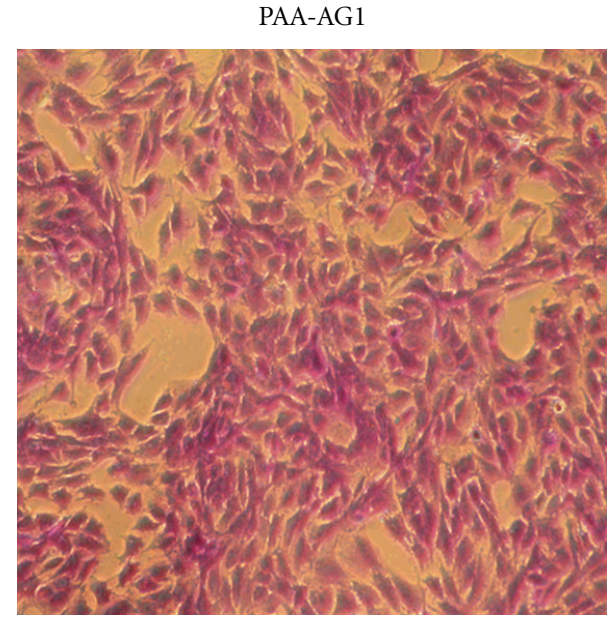

(b)

FIGURE 4: Morphology of mouse embryo fibroblasts grown on PAAAG2 and PAA-AG1 after 10 days of culture [42].

nervous system are common and are a major source of disability, impairing the ability to move muscles and/or feel normal sensations or resulting in painful neuropathies. Due

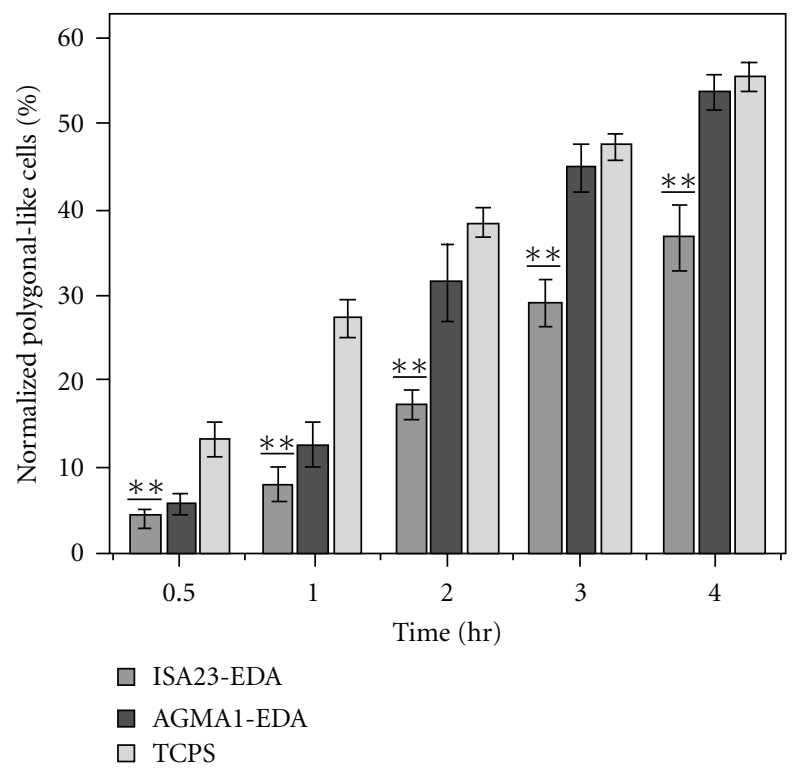

FIGURE 5: MDCK cells adhesion versus time on ISA23-EDA, AGMA1-EDA, and TCPS [62].

to the difficulties in treating such injuries, many patients are left without any benefit of medical intervention. Even among the patients who receive treatment for traumatic peripheral nerve injuries, more than $50 \%$ show no measurable signs of recovery or else suffer from drastically reduced muscle strength [74].

After nerve trauma, the standard clinical operating procedure consists of opposing the two nerve ends and suture them together without generating tension where possible. When the defect is so large that the severed nerve ends cannot be directly sutured, nerve injury is bridged by autologous nerve grafting. While autografts are the best clinical bridges available today because they are biocompatible, nontoxic and provide a support structure to promote axonal adhesion, there are many drawbacks to this procedure. These include the need for a secondary surgery, loss of donor site function, limited availability, modality mismatch (arising from a sensory nerve being used to repair a motor or mixed nerve), and neuroma formation at the donor or graft site.

Various tissue engineering strategies have been used to influence different aspects of the regenerative process with hope for functional recovery using natural and synthetic tubular scaffolds. The design criteria for fabrication of scaffolds should address various factors including composition [75] and dimensions of the tubular scaffold [76], the addition of exogenous factors such as fibrin precursors [77] and growth factors, the incorporation of glial cells, most often Schwann cells and fibroblasts [78, 79], the elastic modulus, permeability, topography, swelling ratio, degradation rate, size, and clearance of the degradation products [80]. In particular the elastic modulus of the scaffold should be at least $1,200 \mathrm{kPa}$ in order to resist compressive and tensile forces that are generated both during the surgery as well as from surrounding tissue after implantation [81]. Different 
ISA23-EDA
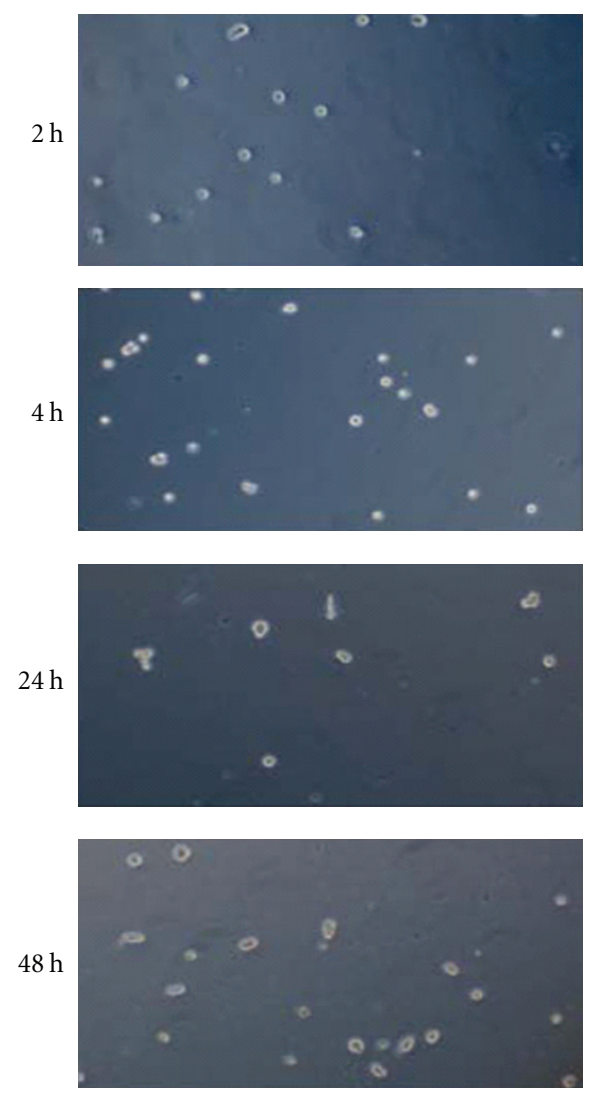

FIGURE 6: Optical microscopy images showing time evolution of MDCK cells on ISA23-EDA, AGMA1-EDA and TCPS [62].
AGMA1-EDA
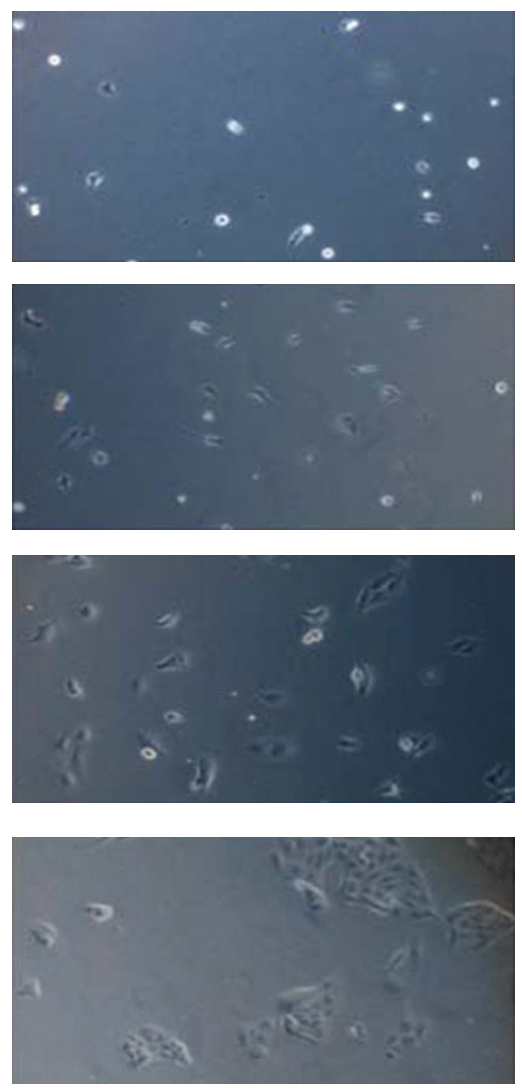

TCPS
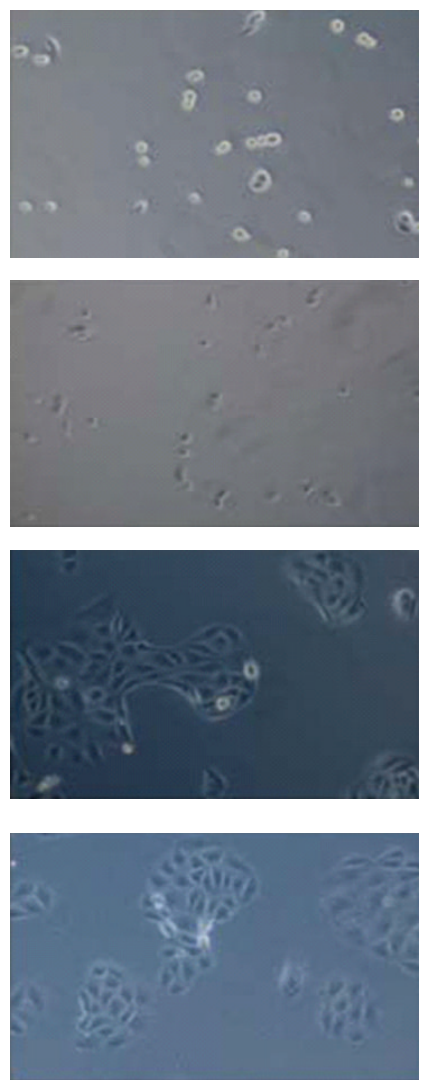

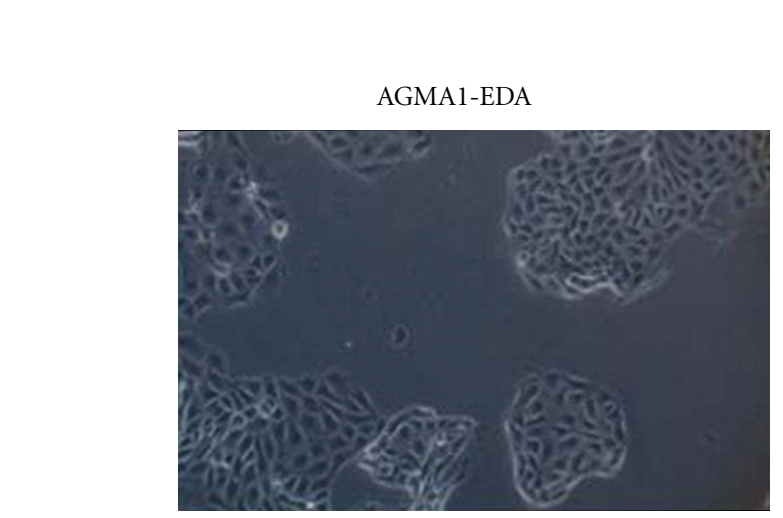

(a)

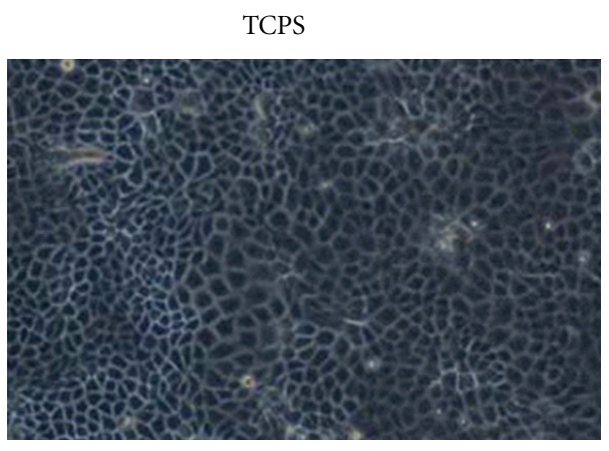

(b)

FigURE 7: Optical microscopy images showing MDCK on TCPS and AGMA1-EDA at 72 hour after seeding [62].

natural and synthetic materials have been used to facilitate nerve regeneration. Among natural tubular scaffolds, autogenous venous and arterial nerve grafts have been the most successful in achieving functional recovery across $10-\mathrm{mm}$ nerve gaps [82-84]. Venous grafts remain intact throughout the process of nerve regeneration and are easier to extract compared to arterial grafts [82]. While natural materials have good biocompatibility, they often collapse when used in longer nerve gaps. Additionally, issues related to the limited availability of these explants, as well as autograft- triggered immune response, are a few among many reasons that prompted exploration of alternative materials to direct nerve growth [85]. Synthetic tubular scaffolds have similar advantages to natural scaffolds but additionally provide mechanical and structural control [86]. In the recent past, several guidance techniques using artificial nerve conduits have been developed to guide nerve regeneration towards the distal stump [87]. The isolated environment provided by guidance channels helps confinement and concentrate neurotrophic factors that are released by supporting cells 
Actin
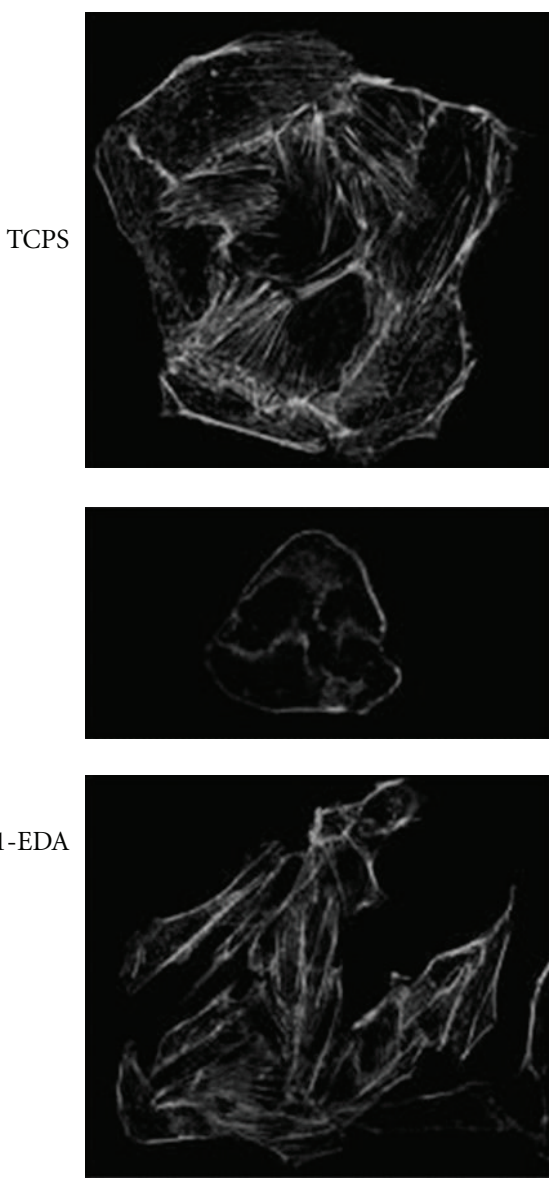

ISA23-EDA

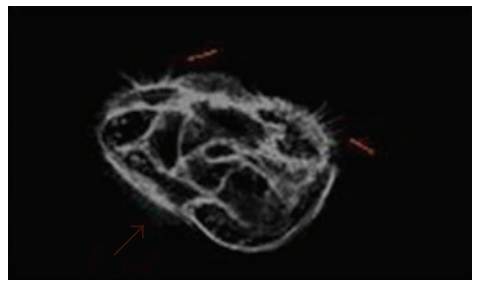

Vinculin
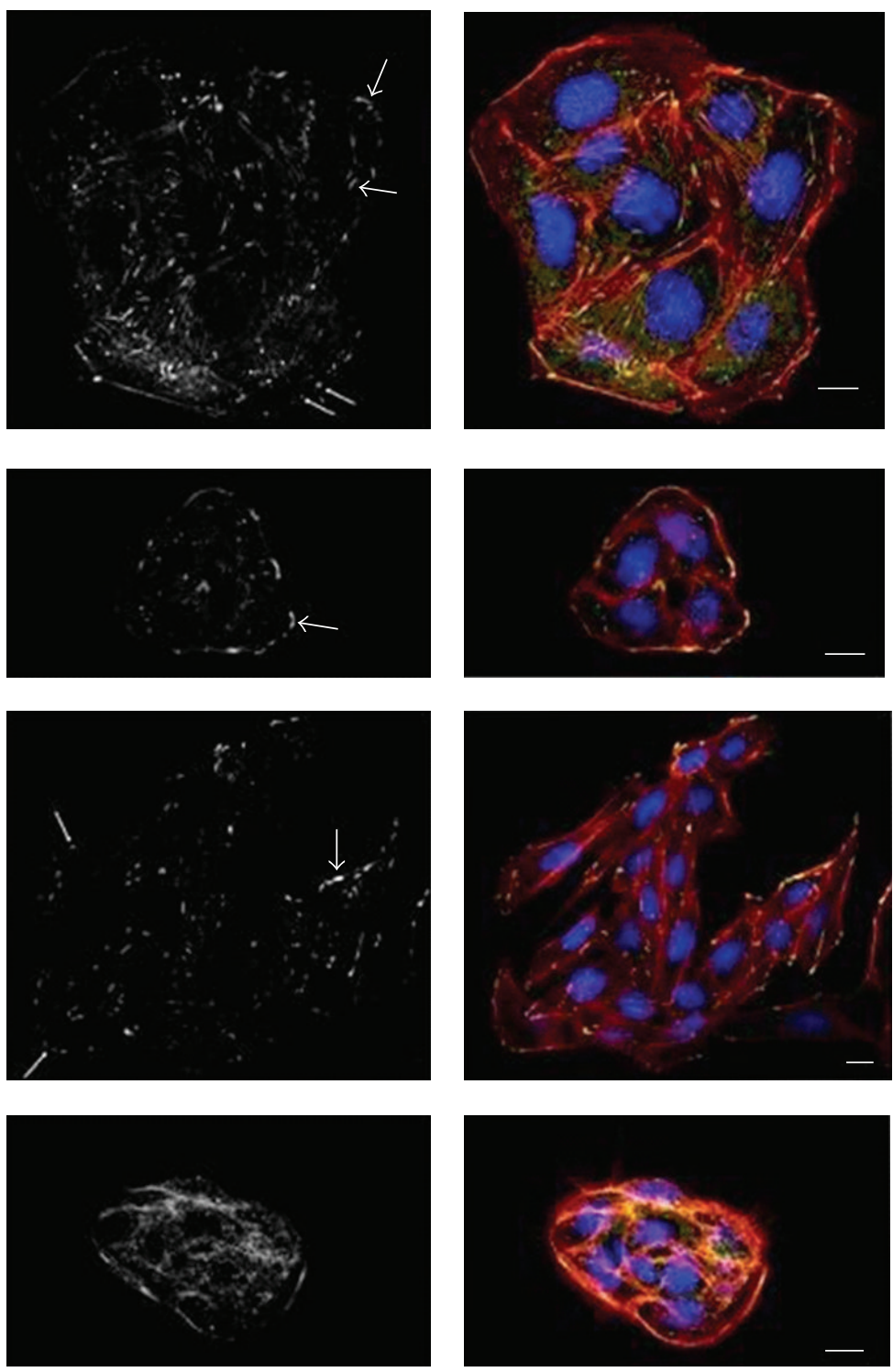

FIGURE 8: Immunofluorescence analysis of actin cytoskeleton and focal contacts of TCPS or hydrogel MDCK growing cells [62].

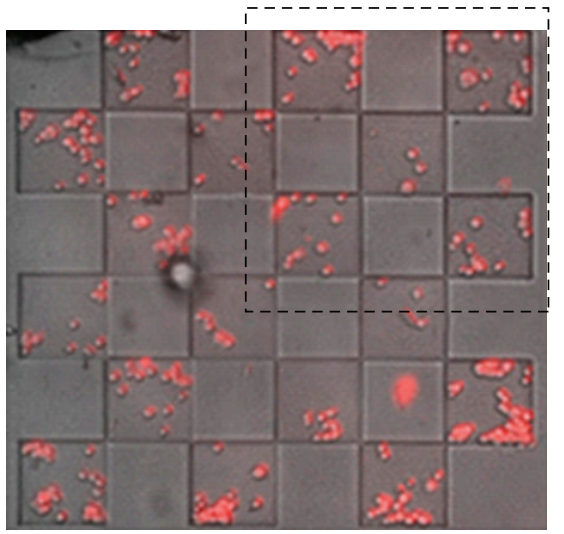

(a)

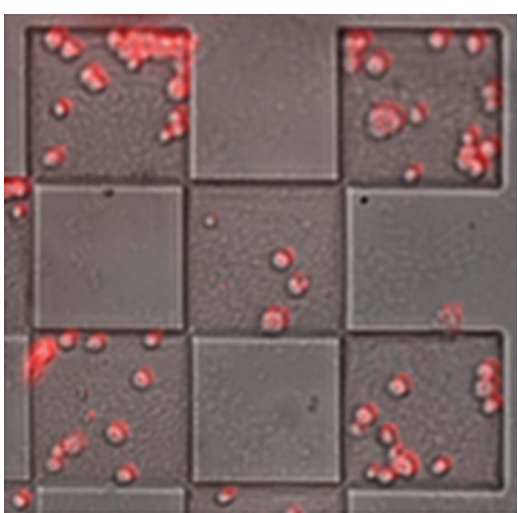

(b)

FIGURE 9: PC12 adhesion on electron-beam-exposed areas [63]. 


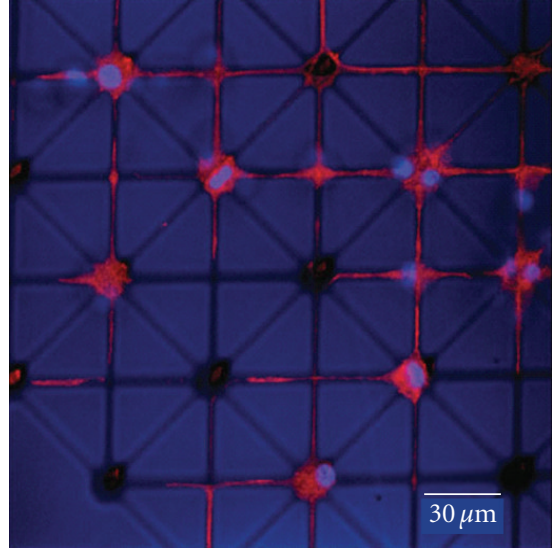

(a)

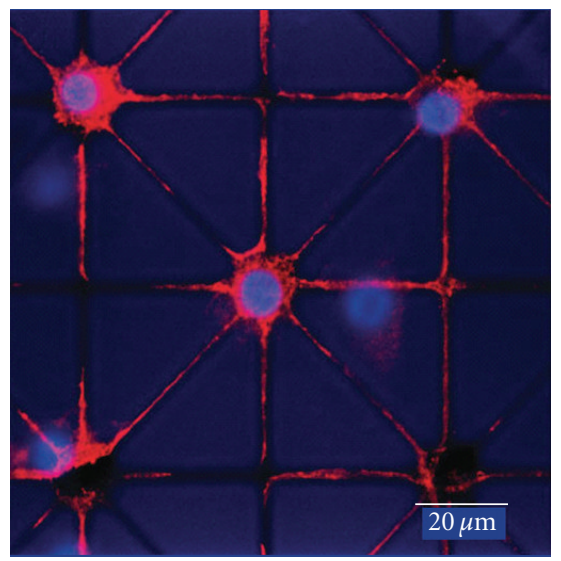

(b)

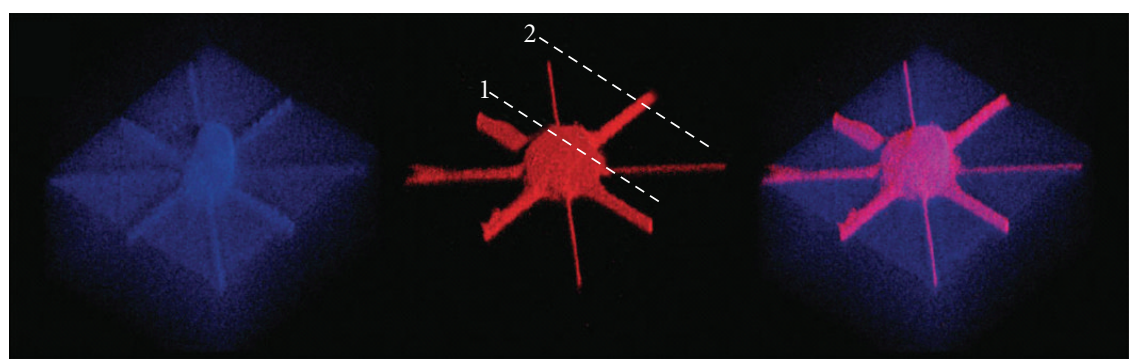

(c)

Figure 10: Confocal microscopy images of PC12 cells grown on electron-beam-lithography-patterned network of microwells (10 mm diameter) connected by microchannels ( $1 \mathrm{~mm}$ width). The cells were treated with NGF (for 48 hours) and immunostained with DAPI (cell nuclei, blue), FITC antivinculin antibody (focal contacts, red), and TRITC phalloidin (actin filaments, red) [63].

while protecting the axons against collapse and invasion from immune cells [82]. The use of guidance channels eliminates functional loss at the donor site, a condition that is commonly associated to autografts. Initial studies employing the use of short impermeable silicone tubes have shown promising nerve regeneration across $3 \mathrm{~mm}$ gaps [88], although significant fibrosis and nerve compression have been subsequently associated with the use of these tubes [89-91]. Biodegradable polymers such as poly(L-lactic acid), polyglycolic acid, and poly(lactic-co-glycolic) acid have been originally the materials of choice for synthesizing conduits, due to their relative abundance and applicability [92-101]. In addition to poly(esters), biodegradable poly(urethane) [102-104], poly(organo-phosphazene) [16], and poly(3hydroxybutyrate) [105-107] have shown a capacity for guiding regeneration. Nevertheless, these materials do not fulfill all the requirements that a scaffold for in vivo application should have. For instance, a common inconvenience of biodegradable polyesters is to cause inflammation in the surrounding tissues giving rise to a local concentration of acids upon degradation.

In recent years, special attention has been given to hydrogels. Hydrogels exhibit overall properties similar to those of soft tissues, having tunable elasticity, nutrient permeability, biocompatibility, and low interfacial tension. Among natural hydrogels, gelatin-based tubular scaffolds [108], alginatebased capillary hydrogels [109], and multichannel collagen nerve conduits [110] have been used to guide axonal growth in animal experiments. Synthetic hydrogels include PEG [111] and poly(2-hydroxyethyl methacrylate-co-methyl methacrylate) [112]. Although these materials have shown promising results in terms of nerve regeneration, their properties such as permeability, degradability, and mechanical strength are not yet satisfactory [113].

AGMA1-EDA hydrogels have a definite potential as biomimetic materials and deserve to be further considered for different biotechnological applications such as substrates for cell culture [62]. Unfortunately, their mechanical properties are not satisfactory in view of a use as scaffolds for tissue engineering, in that their strength is still very low and they are very soft and breakable on handling. To overcome this problem, a new synthetic method has been developed leading to second-generation AGMA1 hydrogels with similar composition and exhibiting the same biological properties but with improved mechanical strength [64]. In particular, a different two-step synthetic pathway has been followed as reported in Scheme 4. In the first step an acryloyl end-capped linear AGMA1 oligomer is synthesized using a controlled excess of the bisacrylamide; in the second step the oligomer is photopolymerized by UV irradiation producing AGMA1-UV hydrogels with the required mechanical characteristics.

Hydrogel tubes of different dimensions (length 10$30 \mathrm{~mm}, 3 \mathrm{~mm}$ external diameter, and $0.5-1.2 \mathrm{~mm}$ internal 


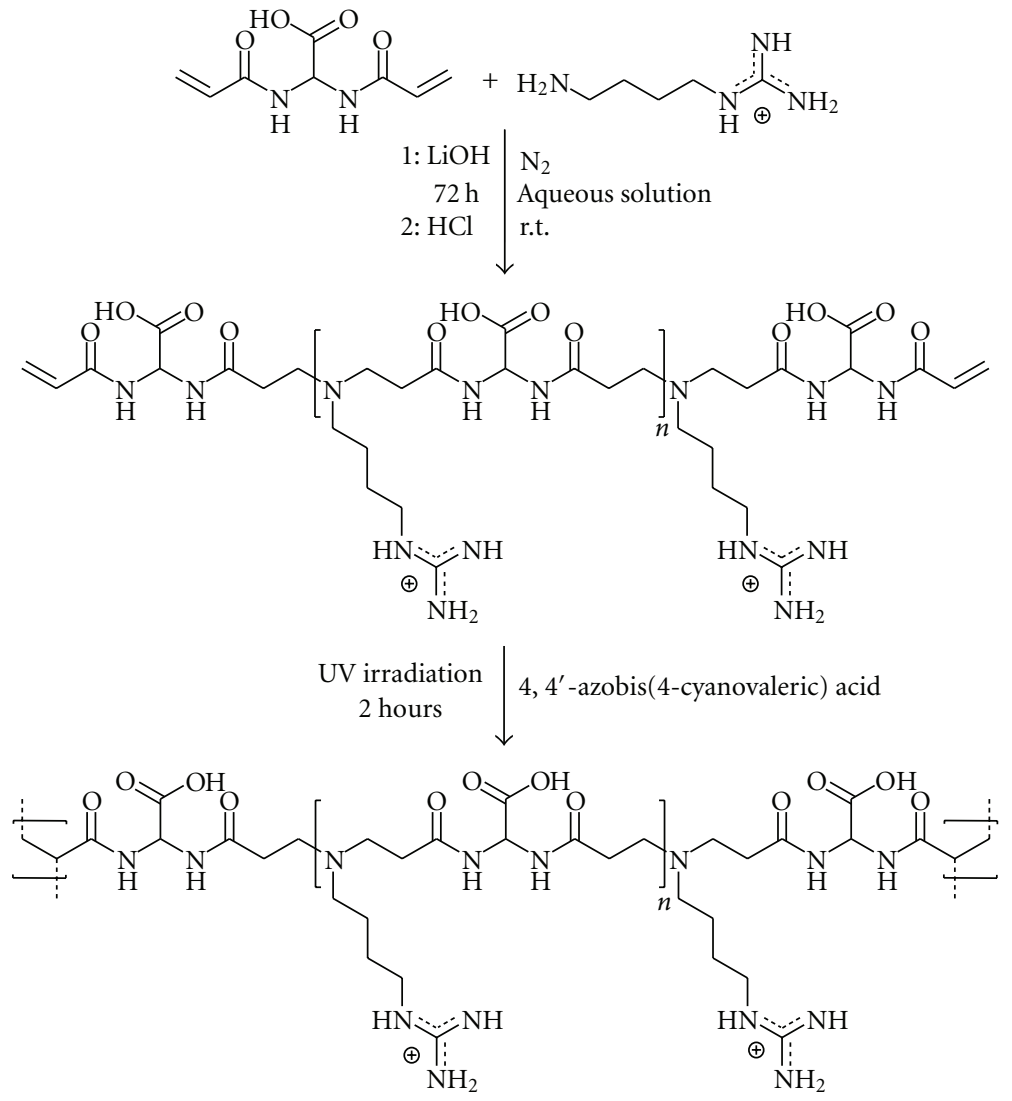

Scheme 4: Synthetic pathway leading to AGMA1 hydrogels.

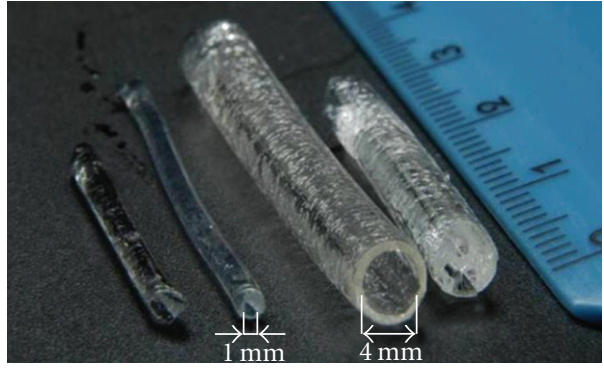

(a)

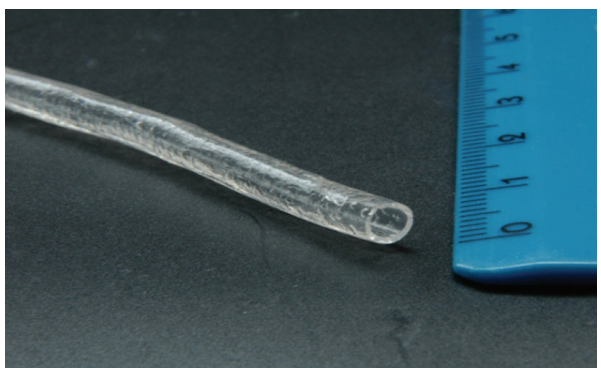

(b)

FIGURE 11: AGMA1 tubular hydrogels obtained by UV photopolymerization [64].

diameter) are obtained (Figure 11); however, the preferred dimensions for rat implantation are $10 \mathrm{~mm}$ length and $1 \mathrm{~mm}$ inner diameter [64].

Cross-linked PAAs, obtained by ethylenediamine as cross-linking agent, swell in water giving very soft hydrogels $[33,42,62,65]$. Swelling tests carried out on the AGMA1-UV hydrogels in doubly distilled water and 0.1 M PBS solution pH 7.4 show a $200 \%$ absorption in both cases, 3 times lower than the AGMA1-EDA hydrogels.

AGMA1-UV tubular scaffolds have been tested in vivo as conduit for nerve regeneration in living rats. The right sciatic nerve of the rats has been cut in the middle, and hydrogel conduit having $10 \mathrm{~mm}$ length and $1 \mathrm{~mm}$ inner diameters implanted leaving the nerve gap of $5 \mathrm{~mm}$ (Figure 12). All rats have survived, and no complications related to operation occurred, since all wounds have healed spontaneously [64].

The progression of the nerve regeneration has been extensively analyzed at different time points, namely, 30, 90, and 180 days after surgery [64]. 30 days after implantation the conduit appears well integrated and no dislocations are observed. The regenerated nerve is resistant to mechanical traction showing no evidence of interruption. No apparent signs of inflammatory reaction or serum infiltrate are found, even if a thin fibrotic sheet surrounding the conduit is observed. Regeneration between the upper and lower nerve stump occurs inside the scaffold guide as demonstrated by 

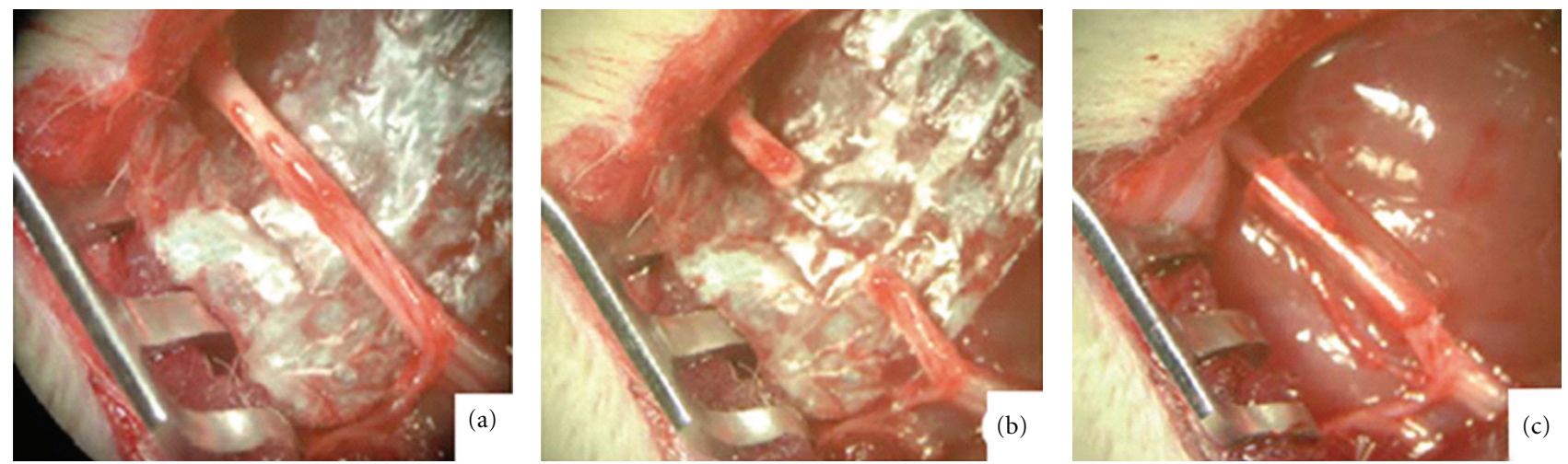

FIGURE 12: Normal intact right sciatic nerve was cut in the middle (a), removing 4-5 mm nervous tissue. AGMA1 hydrogel tube has been used to regenerate the gap (c) [64].

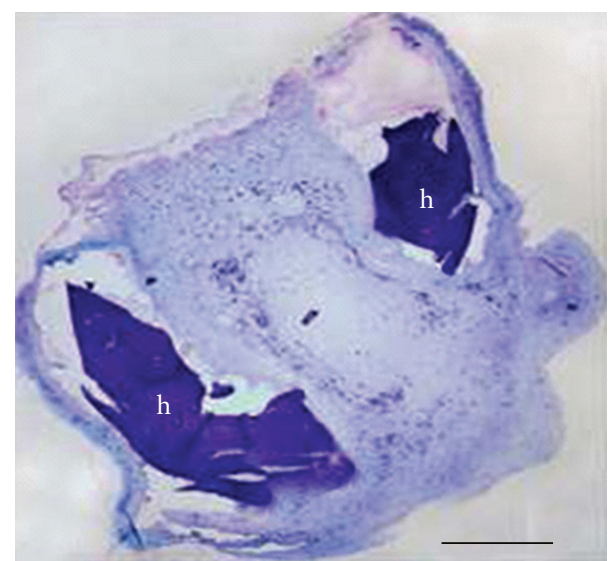

(a)

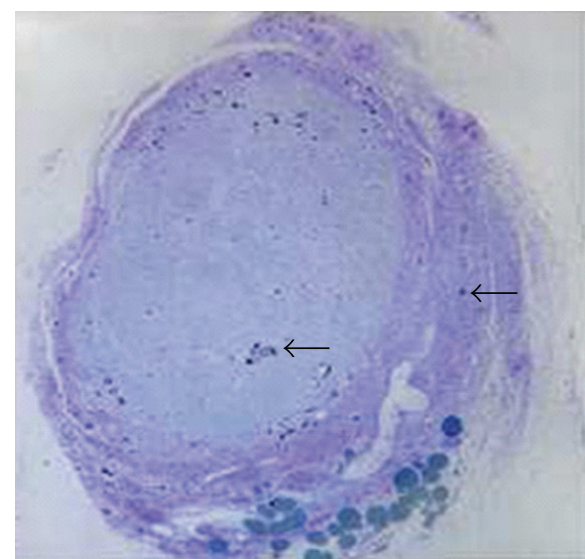

(b)

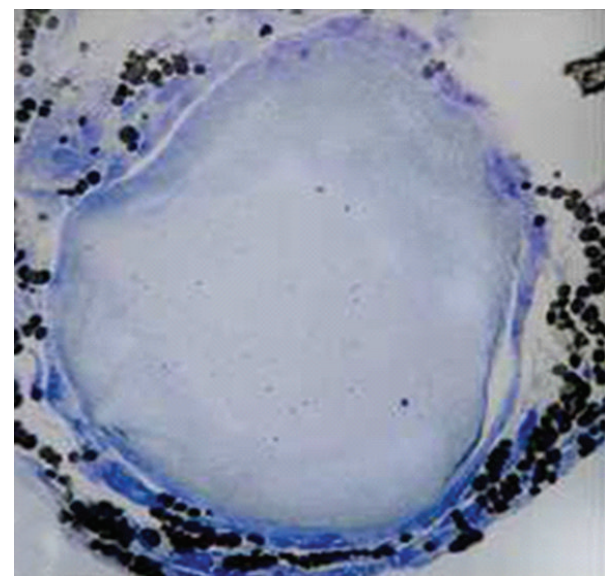

(c)

FIGURE 13: Toluidine-blue semithin transverse section of regenerating nerves in the medial part of the nerve guide at 30 (a), 90 (b), and 180 (c) days after surgery [64].

the presence of nerve fibers filling the original gap. The conduit is largely degraded but not completely reabsorbed, since two large scaffold fragments (h) are embedded in the epineurium surrounding the nerve (Figure 13(a)). At 90 days after surgery, a complete nerve structure is evident with some detritus still included in the fibrotic tissue around the nerve
(Figure 13(b)), whereas at 180 days the scaffold is grossly reabsorbed, with only a few detritus in the surrounding epineurium (Figure 13(c)).

Morphological evaluations have been focused on 30 days after surgery, since the nerve regeneration is apparently satisfactory and not significantly different from that observed 


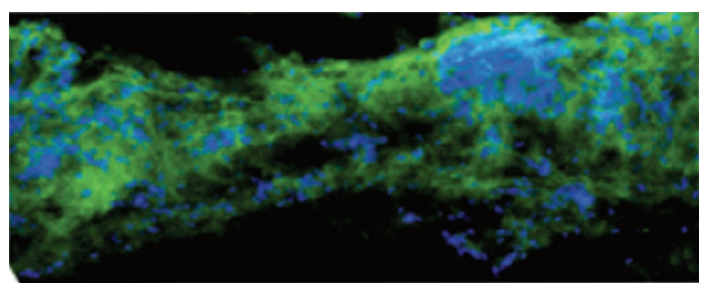

(a)

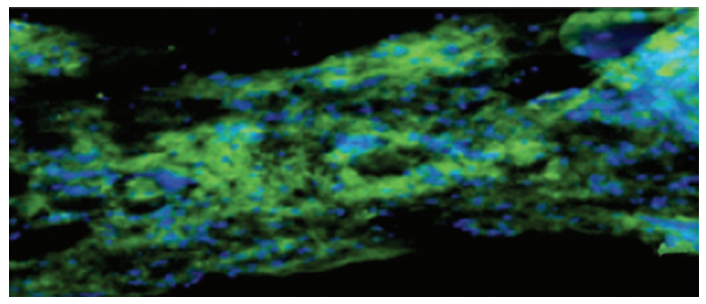

(b)

FIGURE 14: Immunofluorescence image of the regenerated nerve inside the hydrogel tube at 30 (a) and 90 (b) days after surgery [64].

at 90 and 180 days after implantation [64]. The axonal regeneration at 30 days is confirmed by immunofluorescent analysis of longitudinal sections of the sciatic nerve stump through the conduit.

Nerve fibers have been labeled in green with anti neurofilament $\mathrm{M} / \mathrm{H}$ antibody and Schwann cells nuclei stained in blue with nuclear marker DAPI. Figure 14(a) shows the continuity of green labeling for the heavy chain of axon neurofilaments. A stronger neurofilament immunopositivity at 90 days after surgery is consistent with a higher, complete axonal regeneration (Figure 14(b)).

\section{Conclusions and Perspectives}

PAAs constitute a family of highly hydrophilic ionic polymers that are easily synthesized and can be designed to be biocompatible and degradable in the body fluids. Linear PAAs are usually water soluble. Cross-linked PAAs can be obtained by several means, forming highly swollen hydrogels some of which definitely warrant potential as scaffolds for tissue engineering applications both in vitro and in vivo, being highly biocompatible and biodegradable to nontoxic, selfbuffered products that do not elicit inflammatory response from the surrounding tissues.

In more general terms, PAAs are highly versatile functional polymers whose biotechnological applications are still waiting to be fully exploited.

\section{Abbreviations}

PAAs: Poly(amidoamine)s

I.P.: Isoelectric point

EPR: Enhanced permeation and retention effect

BAC: 2,2-bis(acrylamido) acetic acid

EDA: Ethylenediamine

RGD: Tripeptide arginine-glycine-aspartic acid
PHEMA: Poly(2-hydroxyethyl methacrylate)
PEG: $\quad$ Poly(ethylene glycol)
ECM: Extracellular matrix
TCPS: Tissue culture polystyrene plates
MDCK: Madin-Darby canine kidney cell line
FITC: Fluorescein Isothiocyanate
TRITC: Tetramethylrhodamine isothiocyanate
BSA: Bovine serum albumin
EGF: Epidermal growth factor
PC12: Rat pheochromocytoma cell line
NGF: Nerve growth factor
DAPI: $\quad$ 4',6-diamidino-2-phenylindole.

\section{Acknowledgment}

This work has been supported by Fondazione CARIPLO under the Project "Functional Polymeric Hydrogels for Tissue Regeneration" (no. 2010-0501), call for the Scientific Research on Advanced Materials, 2010.

\section{References}

[1] S. J. Shieh and J. P. Vacanti, "State-of-the-art tissue engineering: from tissue engineering to organ building," Surgery, vol. 137, no. 1, pp. 1-7, 2005.

[2] Italian Ministry of Health, National Center for Transplant, 2009-2010.

[3] R. Langer and J. P. Vacanti, “Tissue engineering," Science, vol. 260, no. 5110, pp. 920-926, 1993.

[4] J. P. Vacanti and R. Langer, "Tissue engineering: the design and fabrication of living replacement devices for surgical reconstruction and transplantation," The Lancet, vol. 354, no. 1, pp. 32-34, 1999.

[5] R. S. Langer and J. P. Vacanti, "Tissue engineering: the challenges ahead," Scientific American, vol. 280, no. 4, pp. 86-89, 1999.

[6] R. Langer and J. P. Vacanti, "Artificial organs," Scientific American, vol. 273, no. 3, pp. 130-133, 1995.

[7] S. Yang, K. F. Leong, Z. Du, and C. K. Chua, "The design of scaffolds for use in tissue engineering. Part I. Traditional factors," Tissue Engineering, vol. 7, no. 6, pp. 679-689, 2001.

[8] M. H. Spilker, K. Asano, I. V. Yannas, and M. Spector, "Contraction of collagen-glycosaminoglycan matrices by peripheral nerve cells in vitro," Biomaterials, vol. 22, no. 10, pp. 1085-1093, 2001.

[9] J. D. Guest, A. Rao, L. Olson, M. B. Bunge, and R. P. Bunge, "The ability of human schwann cell grafts to promote regeneration in the transected nude rat spinal cord," Experimental Neurology, vol. 148, no. 2, pp. 502-522, 1997.

[10] W. J. C. M. Marijnissen, G. J. V. M. Van Osch, J. Aigner et al., "Alginate as a chondrocyte-delivery substance in combination with a non-woven scaffold for cartilage tissue engineering," Biomaterials, vol. 23, no. 6, pp. 1511-1517, 2002.

[11] B. Pomahač, T. Svensjö, F. Yao, H. Brown, and E. Eriksson, "Tissue engineering of skin," Critical Reviews in Oral Biology and Medicine, vol. 9, no. 3, pp. 333-334, 1998. 
[12] S. Liu, P. Peulve, O. Jin et al., "Axonal regrowth through collagen tubes bridging the spinal cord to nerve roots," Journal of Neuroscience Research, vol. 49, no. 4, pp. 425-432, 1997.

[13] X. M. Xu, S. X. Zhang, H. Li, P. Aebischer, and M. Bunge, "Regrowth of axons into the distal spinal cord through a Schwann-cell-seeded mini-channel implanted into hemisected adult rat spinal cord," European Journal of Neuroscience, vol. 11, no. 5, pp. 1723-1740, 1999.

[14] A. L. Sieminski, R. F. Padera, T. Blunk, and K. J. Gooch, "Systemic delivery of human growth hormone using genetically modified tissue-engineered microvascular networks: prolonged delivery and endothelial survival with inclusion of nonendothelial cells," Tissue Engineering, vol. 8, no. 6, pp. 1057-1069, 2002.

[15] A. Dar, M. Shachar, J. Leor, and S. Cohen, "Optimization of cardiac cell seeding and distribution in 3D porous alginate scaffolds," Biotechnology and Bioengineering, vol. 80, no. 3, pp. 305-312, 2002.

[16] N. Nicoli Aldini, M. Fini, M. Rocca, G. Giavaresi, and R. Giardino, "Guided regeneration with resorbable conduits in experimental peripheral nerve injuries," International Orthopaedics, vol. 24, no. 3, pp. 121-125, 2000.

[17] Y. L. Jae, J. W. Lee, and C. E. Schmidt, "Neuroactive conducting scaffolds: nerve growth factor conjugation on active ester-functionalized polypyrrole," Journal of the Royal Society Interface, vol. 6, no. 38, pp. 801-810, 2009.

[18] R. A. Dubin, G. C. Callegari, J. Kohn, and A. V. Neimark, "Carbon nanotube fibers are compatible with mammalian cells and neurons," IEEE Transactions on Nanobioscience, vol. 7, no. 1, pp. 11-14, 2008.

[19] E. B. Malarkey and V. Parpura, "Applications of carbon nanotubes in neurobiology," Neurodegenerative Diseases, vol. 4, no. 4, pp. 292-299, 2007.

[20] G. Cellot, E. Cilia, S. Cipollone et al., "Carbon nanotubes might improve neuronal performance by favouring electrical shortcuts," Nature Nanotechnology, vol. 4, no. 2, pp. 126-133, 2009.

[21] W. J. Li and R. S. Tuan, "Polymeric scaffolds for cartilage tissue engineering," Macromolecular Symposia, vol. 227, pp. 65-75, 2005.

[22] W. T. Godbey, "Polymeric scaffolds for stem cell growth," Australian Journal of Chemistry, vol. 58, no. 10, pp. 689-690, 2005.

[23] C. Alexander and K. M. Shakesheff, "Responsive polymers at the biology/materials science interface," Advanced Materials, vol. 18, no. 24, pp. 3321-3328, 2006.

[24] K. Y. Lee and D. J. Mooney, "Hydrogels for tissue engineering," Chemical Reviews, vol. 101, no. 7, pp. 1869-1879, 2001.

[25] P. Ferruti, "Ion-chelating polymers (Medical Applications)," in Polymeric Materials Encyclopedia, J. C. Salamone, Ed., pp. 3334-3359, CRC Press, Boca Raton, Fla, USA, 1996.

[26] P. Ferruti, M. A. Marchisio, and R. Duncan, "Poly(amidoamine)s: biomedical applications," Macromolecular Rapid Communications, vol. 23, no. 5-6, pp. 332-355, 2002.

[27] M. Casali, S. Riva, and P. Ferruti, "Use of new aminosugar derivatives as comonomers for the synthesis of glycosylated poly(amido-amines)," Journal of Bioactive and Compatible Polymers, vol. 16, no. 6, pp. 479-491, 2001.

[28] E. Ranucci, F. Bignotti, P. L. Paderno, and P. Ferruti, "Modification of albumins by grafting poly(amido amine) chains," Polymer, vol. 36, no. 15, pp. 2989-2994, 1995.

[29] P. Ferruti, M. E. Ranucci, L. Sartore et al., "Recent results on functional polymers and macromonomers of interest as biomaterials or for biomaterial modification," Biomaterials, vol. 15, no. 15, pp. 1235-1241, 1994.

[30] N. Lavignac, M. Lazenby, P. Foka et al., "Synthesis and endosomolytic properties of poly(amidoamine) block copolymers," Macromolecular Bioscience, vol. 4, no. 10, pp. 922-929, 2004.

[31] E. Ranucci, P. Ferruti, E. Lattanzio et al., "Acid-base properties of Poly(amidoamine)s," Journal of Polymer Science, Part A, vol. 47, no. 24, pp. 6977-6991, 2009.

[32] S. Richardson, P. Ferruti, and R. Duncan, "Poly(amidoamine)s as potential endosomolytic polymers: evaluation in vitro and body distribution in normal and tumour-bearing animals," Journal of Drug Targeting, vol. 6, no. 6, pp. 391-404, 1999.

[33] P. Ferruti, S. Bianchi, E. Ranucci, F. Chiellini, and V. Caruso, "Novel poly(amido-amine)-based hydrogels as scaffolds for tissue engineering," Macromolecular Bioscience, vol. 5, no. 7, pp. 613-622, 2005.

[34] B. Malgesini, I. Verpilio, R. Duncan, and P. Ferruti, "Poly(amido-amine)s carrying primary amino groups as side substituents," Macromolecular Bioscience, vol. 3, no. 1, pp. 59-66, 2003.

[35] P. Ferruti, E. Ranucci, S. Bianchi, L. Falciola, P. R. Mussini, and M. Rossi, "Novel polyamidoamine-based hydrogel with an innovative molecular architecture as a $\mathrm{Co}^{2+}-, \mathrm{Ni}^{2+}$, and $\mathrm{Cu}^{2+}$ sorbing material: cyclovoltammetry and extended X-ray absorption fine structure studies," Journal of Polymer Science, Part A, vol. 44, no. 7, pp. 2316-2327, 2006.

[36] S. P. Massia and J. A. Hubbell, "An RGD spacing of $440 \mathrm{~nm}$ is sufficient for integrin $\alpha(\mathrm{v}) \beta 3$-mediated fibroblast spreading and $140 \mathrm{~nm}$ for focal contact and stress fiber formation," The Journal of Cell Biology, vol. 114, no. 5, pp. 1089-1100, 1991.

[37] K. Tanahashi, S. Jo, and A. G. Mikos, "Synthesis and characterization of biodegradable cationic poly(propylene fumarate-co-ethylene glycol) copolymer hydrogels modified with agmatine for enhanced cell adhesion," Biomacromolecules, vol. 3, no. 5, pp. 1030-1037, 2002.

[38] W. Raasch, U. Schäfer, J. Chun, and P. Dominiak, "Biological significance of agmatine, an endogenous ligand at imidazoline binding sites," British Journal of Pharmacology, vol. 133, no. 6, pp. 755-780, 2001.

[39] J. Franchini, E. Ranucci, P. Ferruti, M. Rossi, and R. Cavalli, "Synthesis, physicochemical properties, and preliminary biological characterizations of a novel amphoteric agmatinebased poly(amidoamine) with RGD-like repeating units," Biomacromolecules, vol. 7, no. 4, pp. 1215-1222, 2006.

[40] P. Ferruti, J. Franchini, M. Bencini et al., "Prevailingly cationic agmatine-based amphoteric polyamidoamine as a nontoxic, nonhemolytic, and "stealthlike" DNA complexing agent and transfection promoter," Biomacromolecules, vol. 8, no. 5, pp. 1498-1504, 2007.

[41] R. Annunziata, J. Franchini, E. Ranucci, and P. Ferruti, "Structural characterisation of poly(amidoamine) networks via high-resolution magic angle spinning NMR," Magnetic Resonance in Chemistry, vol. 45, no. 1, pp. 51-58, 2007.

[42] P. Ferruti, S. Bianchi, E. Ranucci, F. Chiellini, and A. M. Piras, "Novel agmatine-containing poly(amidoamine) hydrogels as scaffolds for tissue engineering," Biomacromolecules, vol. 6, no. 4, pp. 2229-2235, 2005.

[43] F. Bignotti, P. Sozzani, E. Ranucci, and P. Ferruti, "NMR studies, molecular characterization, and degradation behavior of poly(amido amine)s. 1. Poly(amido amine) deriving 
from the polyaddition of 2-methylpiperazine to 1,4-bis(acryloyl)piperazine," Macromolecules, vol. 27, no. 24, pp. 7171-7178, 1994.

[44] E. Ranucci, G. Spagnoli, P. Ferruti, D. Sgouras, and R. Duncan, "Poly(amidoamine)s with potential as drug carriers: degradation and cellular toxicity," Journal of Biomaterials Science, vol. 2, no. 4, pp. 303-315, 1991.

[45] J. C. Adams, "Cell-matrix contact structures," Cellular and Molecular Life Sciences, vol. 58, no. 3, pp. 371-392, 2001.

[46] J. El-Ali, P. K. Sorger, and K. F. Jensen, "Cells on chips," Nature, vol. 442, no. 7101, pp. 403-411, 2006.

[47] N. Scharnagl, S. Lee, B. Hiebl, A. Sisson, and A. Lendlein, "Design principles for polymers as substratum for adherent cells," Journal of Materials Chemistry, vol. 20, no. 40, pp. 8789-8802, 2010.

[48] M. P. Lutolf and J. A. Hubbell, "Synthetic biomaterials as instructive extracellular microenvironments for morphogenesis in tissue engineering," Nature Biotechnology, vol. 23, no. 1, pp. 47-55, 2005.

[49] P. Krsko and M. Libera, "Biointeractive hydrogels," Materials Today, vol. 8, no. 12, pp. 36-44, 2005.

[50] V. L. Tsang, A. A. Chen, L. M. Cho et al., "Fabrication of 3D hepatic tissues by additive photopatterning of cellular hydrogels," The FASEB Journal, vol. 21, no. 3, pp. 790-801, 2007.

[51] S. Nayak and L. Andrew Lyon, "Soft nanotechnology with soft nanoparticles," Angewandte Chemie-International Edition, vol. 44, no. 47, pp. 7686-7708, 2005.

[52] M. R. Hynd, J. P. Frampton, N. Dowell-Mesfin, J. N. Turner, and W. Shain, "Directed cell growth on proteinfunctionalized hydrogel surfaces," Journal of Neuroscience Methods, vol. 162, no. 1-2, pp. 255-263, 2007.

[53] F. Toyoshima and E. Nishida, "Integrin-mediated adhesion orients the spindle parallel to the substratum in an EB1- and myosin X-dependent manner," The EMBO Journal, vol. 26, no. 6, pp. 1487-1498, 2007.

[54] E. Ruoslahti, "RGD and other recognition sequences for integrins," Annual Review of Cell and Developmental Biology, vol. 12, pp. 697-715, 1996.

[55] U. Hersel, C. Dahmen, and H. Kessler, "RGD modified polymers: biomaterials for stimulated cell adhesion and beyond," Biomaterials, vol. 24, no. 24, pp. 4385-4415, 2003.

[56] T. G. Kim and T. G. Park, "Biomimicking extracellular matrix: cell adhesive RGD peptide modified electrospun poly(D,L-lactic-co-glycolic acid) nanofiber mesh," Tissue Engineering, vol. 12, no. 2, pp. 221-233, 2006.

[57] P. M. D. Watson, M. J. Humphries, J. Relton, N. J. Rothwell, A. Verkhratsky, and R. M. Gibson, "Integrin-binding RGD peptides induce rapid intracellular calcium increases and MAPK signaling in cortical neurons," Molecular and Cellular Neuroscience, vol. 34, no. 2, pp. 147-154, 2007.

[58] S. Kostidis, A. Stavrakoudis, N. Biris, D. Tsoukatos, C. Sakarellos, and V. Tsikaris, "The relative orientation of the Arg and Asp side chains defined by a pseudodihedral angle as a key criterion for evaluating the structure-activity relationship of RGD peptides," Journal of Peptide Science, vol. 10, no. 8, pp. 494-509, 2004.

[59] E. Puklin-Faucher, M. Gao, K. Schulten, and V. Vogel, "How the headpiece hinge angle is opened: new insights into the dynamics of integrin activation," The Journal of Cell Biology, vol. 175, no. 2, pp. 349-360, 2006.

[60] W. A. Comisar, S. X. Hsiong, H. J. Kong, D. J. Mooney, and J. J. Linderman, "Multi-scale modeling to predict ligand presentation within RGD nanopatterned hydrogels," Biomaterials, vol. 27, no. 10, pp. 2322-2329, 2006.

[61] A. Bodin, L. Ahrenstedt, H. Fink, H. Brumer, B. Risberg, and P. Gatenholm, "Modification of nanocellulose with a xyloglucan-RGD conjugate enhances adhesion and proliferation of endothelial cells: implications for tissue engineering," Biomacromolecules, vol. 8, no. 12, pp. 3697-3704, 2007.

[62] E. Jacchetti, E. Emilitri, S. Rodighiero et al., "Biomimetic poly(amidoamine) hydrogels as synthetic materials for cell culture," Journal of Nanobiotechnology, vol. 6, article 14, 2008.

[63] G. Dos Reis, F. Fenili, A. Gianfelice et al., "Direct microfabrication of topographical and chemical cues for the guided growth of neural cell networks on polyamidoamine hydrogels," Macromolecular Bioscience, vol. 10, no. 8, pp. 842-852, 2010.

[64] V. Magnaghi, V. Conte, P. Procacci et al., "Biological performance of a novel biodegradable polyamidoamine hydrogel as guide for peripheral nerve regeneration," Journal of Biomedical Materials Research Part A, vol. 98, no. 1, pp. 19-30, 2011.

[65] E. Emilitri, F. Guizzardi, C. Lenardi, M. Suardi, E. Ranucci, and P. Ferruti, "Novel poly(amidoamine)-based hydrogels as scaffolds for tissue engineering," Macromolecular Symposia, vol. 266, no. 1, pp. 41-47, 2008.

[66] G. Maheshwari, G. Brown, D. A. Lauffenburger, A. Wells, and L. G. Griffith, "Cell adhesion and motility depend on nanoscale RGD clustering," Journal of Cell Science, vol. 113, no. 10, pp. 1677-1686, 2000.

[67] E. A. Cavalcanti-Adam, T. Volberg, A. Micoulet, H. Kessler, B. Geiger, and J. P. Spatz, "Cell spreading and focal adhesion dynamics are regulated by spacing of integrin ligands," Biophysical Journal, vol. 92, no. 8, pp. 2964-2974, 2007.

[68] J. C. Adams, "Roles of fascin in cell adhesion and motility," Current Opinion in Cell Biology, vol. 16, no. 5, pp. 590-596, 2004.

[69] J. Melin and S. R. Quake, "Microfluidic large-scale integration: the evolution of design rules for biological automation," Annual Review of Biophysics and Biomolecular Structure, vol. 36, pp. 213-231, 2007.

[70] N. M. Elman, B. C. Masi, M. J. Cima, and R. Langer, "Electro-thermally induced structural failure actuator (ETISFA) for implantable controlled drug delivery devices based on Micro-Electro-Mechanical- Systems," Lab on a Chip, vol. 10, no. 20, pp. 2796-2804, 2010.

[71] Y. Mei, K. Saha, S. R. Bogatyrev et al., "Combinatorial development of biomaterials for clonal growth of human pluripotent stem cells," Nature Materials, vol. 9, no. 9, pp. 768-778, 2010.

[72] L. M. Y. Yu, N. D. Leipzig, and M. S. Shoichet, "Promoting neuron adhesion and growth," Materials Today, vol. 11, no. 5, pp. 36-43, 2008.

[73] L. R. Robinson, "Traumatic injury to peripheral nerves," Muscle and Nerve, vol. 23, no. 6, pp. 863-873, 2000.

[74] S. K. Lee and S. W. Wolfe, "Peripheral nerve injury and repair," The Journal of the American Academy of Orthopaedic Surgeons, vol. 8, no. 4, pp. 243-252, 2000.

[75] P. Aebischer, V. Guenard, S. R. Winn, R. F. Valentini, and P. M. Galletti, "Blind-ended semipermeable guidance channels support peripheral nerve regeneration in the absence of a distal nerve stump," Brain Research, vol. 454, no. 1-2, pp. 179-187, 1988.

[76] L. R. Williams and S. Varon, "Modification of fibrin matrix formation in situ enhances nerve regeneration in silicone chambers," The Journal of Comparative Neurology, vol. 231, no. 2, pp. 209-220, 1985. 
[77] L. R. Williams, N. Danielsen, H. Muller, and S. Varon, "Exogenous matrix percursors promote functional nerve regneration across a $15-\mathrm{mm}$ gap within a silicone chamber in the rat," The Journal of Comparative Neurology, vol. 264, no. 2, pp. 284-290, 1987.

[78] A. D. Ansselin, T. Fink, and D. F. Davey, "Collagen—chitosan nerve guides for peripheral nerve repair: a histomorphometric study," Neuropathology and Applied Neurobiology, vol. 23, pp. 387-398, 1997.

[79] M. Koshimune, K. Takamatsu, H. Nakatsuka, K. Inui, Y. Yamano, and Y. Ikada, "Creating bioabsorbable Schwann cell coated conduits through tissue engineering," Bio-Medical Materials and Engineering, vol. 13, no. 3, pp. 223-229, 2003.

[80] S. Atzet, S. Curtin, P. Trinh, S. Bryant, and B. Ratner, "Degradable poly(2-hydroxyethyl methacrylate)-co-polycaprolactone hydrogels for tissue engineering scaffolds," Biomacromolecules, vol. 9, no. 12, pp. 3370-3377, 2008.

[81] R. Midha, C. A. Munro, P. D. Dalton, C. H. Tator, and M. S. Shoichet, "Growth factor enhancement of peripheral nerve regeneration through a novel synthetic hydrogel tube," Journal of Neurosurgery, vol. 99, no. 3, pp. 555-565, 2003.

[82] P. Weiss, "Reunion of stumps of small nerves by tubulation instead of suture," Science, vol. 93, no. 2403, pp. 67-68, 1941.

[83] M. Foidart-Dessalle, A. Dubuisson, A. Lejeune et al., "Sciatic nerve regeneration through venous or nervous grafts in the rat," Experimental Neurology, vol. 148, no. 1, pp. 236-246, 1997.

[84] C. Y. Tseng, G. Hu, R. T. Ambron, and D. T. W. Chiu, "Histologic analysis of Schwann cell migration and peripheral nerve regeneration in the autogenous venous nerve conduit (AVNC)," Journal of Reconstructive Microsurgery, vol. 19, no. 5, pp. 331-339, 2003.

[85] Y. T. Kim, V. K. Haftel, S. Kumar, and R. V. Bellamkonda, "The role of aligned polymer fiber-based constructs in the bridging of long peripheral nerve gaps," Biomaterials, vol. 29, no. 21, pp. 3117-3127, 2008.

[86] J. S. Belkas, C. A. Munro, M. S. Shoichet, and R. Midha, "Peripheral nerve regeneration through a synthetic hydrogel nerve tube," Restorative Neurology and Neuroscience, vol. 23, no. 1, pp. 19-29, 2005.

[87] N. N. Aldini, G. Perego, G. D. Cella et al., "Effectiveness of a bioabsorbable conduit in the repair of peripheral nerves," Biomaterials, vol. 17, no. 10, pp. 959-962, 1996.

[88] G. Lundborg, L. B. Dahlin, and N. Danielsen, "Ulnar nerve repair by the silicone chamber technique. Case report," Scandinavian Journal of Plastic and Reconstructive Surgery and Hand Surgery, vol. 25, no. 1, pp. 79-82, 1991.

[89] M. Merle, A. L. Dellon, J. N. Campbell, and P. S. Chang, "Complications from silicon-polymer intubulation of nerves," Microsurgery, vol. 10, no. 2, pp. 130-133, 1989.

[90] G. Lundborg, B. Rosén, L. Dahlin, J. Holmberg, and I. Rosén, "Tubular repair of the median or ulnar nerve in the human forearm: a 5-year follow-up," Journal of Hand Surgery, vol. 29, no. 2, pp. 100-107, 2004.

[91] J. Braga-Silva, "The use of silicone tubing in the late repair of the median and ulnar nerves in the forearm," Journal of Hand Surgery, vol. 24, no. 6, pp. 703-706, 1999.

[92] J. S. Belkas, M. S. Shoichet, and R. Midha, "Peripheral nerve regeneration through guidance tubes," Neurological Research, vol. 26, no. 2, pp. 151-160, 2004.
[93] T. W. Hudson, G. R. D. Evans, and C. E. Schmidt, "Engineering strategies for peripheral nerve repair," Clinics in Plastic Surgery, vol. 26, no. 4, pp. 617-628, 1999.

[94] V. B. Doolabh, M. C. Hertl, and S. E. Mackinnon, "The role of conduits in nerve repair: a review," Reviews in the Neurosciences, vol. 7, no. 1, pp. 47-84, 1996.

[95] S. H. Oh, J. H. Kim, K. S. Song et al., "Peripheral nerve regeneration within an asymmetrically porous PLGA/Pluronic F127 nerve guide conduit," Biomaterials, vol. 29, no. 11, pp. 1601-1609, 2008.

[96] Z. H. Zhou, X. P. Liu, and L. H. Liu, "Preparation and biocompatibility of poly(L-lactide-co-glycolide) scaffold materials for nerve conduits," Designed Monomers and Polymers, vol. 11, no. 5, pp. 447-456, 2008.

[97] L. He, Y. Zhang, C. Zeng et al., "Manufacture of plga multiple-channel conduits with precise hierarchical pore architectures and in vitro/vivo evaluation for spinal cord injury," Tissue Engineering Part C, vol. 15, no. 2, pp. 243-255, 2009.

[98] S. Ichihara, Y. Inada, A. Nakada et al., "Development of new nerve guide tube for repair of long nerve defects," Tissue Engineering Part C, vol. 15, no. 3, pp. 387-402, 2009.

[99] M. Yoshitani, S. Fukuda, S. I. Itoi et al., "Experimental repair of phrenic nerve using a polyglycolic acid and collagen tube," Journal of Thoracic and Cardiovascular Surgery, vol. 133, no. 3, pp. 726-733, 2007.

[100] M. C. Lu, Y. T. Huang, J. H. Lin et al., "Evaluation of a multilayer microbraided polylactic acid fiber-reinforced conduit for peripheral nerve regeneration," Journal of Materials Science, vol. 20, no. 5, pp. 1175-1180, 2009.

[101] G. R. D. Evans, K. Brandt, S. Katz et al., "Bioactive poly(Llactic acid) conduits seeded with Schwann cells for peripheral nerve regeneration," Biomaterials, vol. 23, no. 3, pp. 841-848, 2002.

[102] G. Soldani, G. Varelli, A. Minnocci, and P. Dario, "Manufacturing and microscopical characterisation of polyurethane nerve guidance channel featuring a highly smooth internal surface," Biomaterials, vol. 19, no. 21, pp. 1919-1924, 1998.

[103] D. Yin, X. Wang, Y. Yan, and R. Zhang, "Preliminary studies on peripheral nerve regeneration using a new polyurethane conduit," Journal of Bioactive and Compatible Polymers, vol. 22, no. 2, pp. 143-159, 2007.

[104] T. Cui, Y. Yan, R. Zhang, L. Liu, W. Xu, and X. Wang, "Rapid prototyping of a double-layer polyurethane-collagen conduit for peripheral nerve regeneration," Tissue Engineering Part C, vol. 15, no. 1, pp. 1-9, 2009.

[105] R. C. Young, G. Terenghi, and M. Wiberg, "Poly-3-hydroxybutyrate (PHB): a resorbable conduit for long-gap repair in peripheral nerves," British Journal of Plastic Surgery, vol. 55, no. 3, pp. 235-240, 2002.

[106] D. F. Kalbermatten, P. J. Kingham, D. Mahay et al., "Fibrin matrix for suspension of regenerative cells in an artificial nerve conduit," Journal of Plastic, Reconstructive and Aesthetic Surgery, vol. 61, no. 6, pp. 669-675, 2008.

[107] A. Mosahebi, M. Wiberg, and G. Terenghi, "Addition of fibronectin to alginate matrix improves peripheral nerve regeneration in tissue-engineered conduits," Tissue Engineering, vol. 9, no. 2, pp. 209-218, 2003.

[108] E. Gámez, Y. Goto, K. Nagata, T. Iwaki, T. Sasaki, and T. Matsuda, "Photofabricated gelatin-based nerve conduits: nerve tissue regeneration potentials," Cell Transplantation, vol. 13 , no. 5, pp. 549-564, 2004. 
[109] P. Prang, R. Müller, A. Eljaouhari et al., "The promotion of oriented axonal regrowth in the injured spinal cord by alginate-based anisotropic capillary hydrogels," Biomaterials, vol. 27, no. 19, pp. 3560-3569, 2006.

[110] L. Yao, G. C. W. de Ruiter, H. Wang et al., "Controlling dispersion of axonal regeneration using a multichannel collagen nerve conduit," Biomaterials, vol. 31, no. 22, pp. 5789-5797, 2010.

[111] M. B. Runge, M. Dadsetan, J. Baltrusaitis et al., "Development of electrically conductive oligo(polyethylene glycol) fumarate-polypyrrole hydrogels for nerve regeneration," Biomacromolecules, vol. 11, no. 11, pp. 2845-2853, 2010.

[112] J. S. Belkas, C. A. Munro, M. S. Shoichet, M. Johnston, and R. Midha, "Long-term in vivo biomechanical properties and biocompatibility of poly(2-hydroxyethyl methacrylate-comethyl methacrylate) nerve conduits," Biomaterials, vol. 26, no. 14, pp. 1741-1749, 2005.

[113] J. W. Gunn, S. D. Turner, and B. K. Mann, "Polymer gel systems for nerve repair and regeneration," Journal of Biomedical Materials Research Part A, vol. 72, no. 1, pp. 91-97, 2005. 

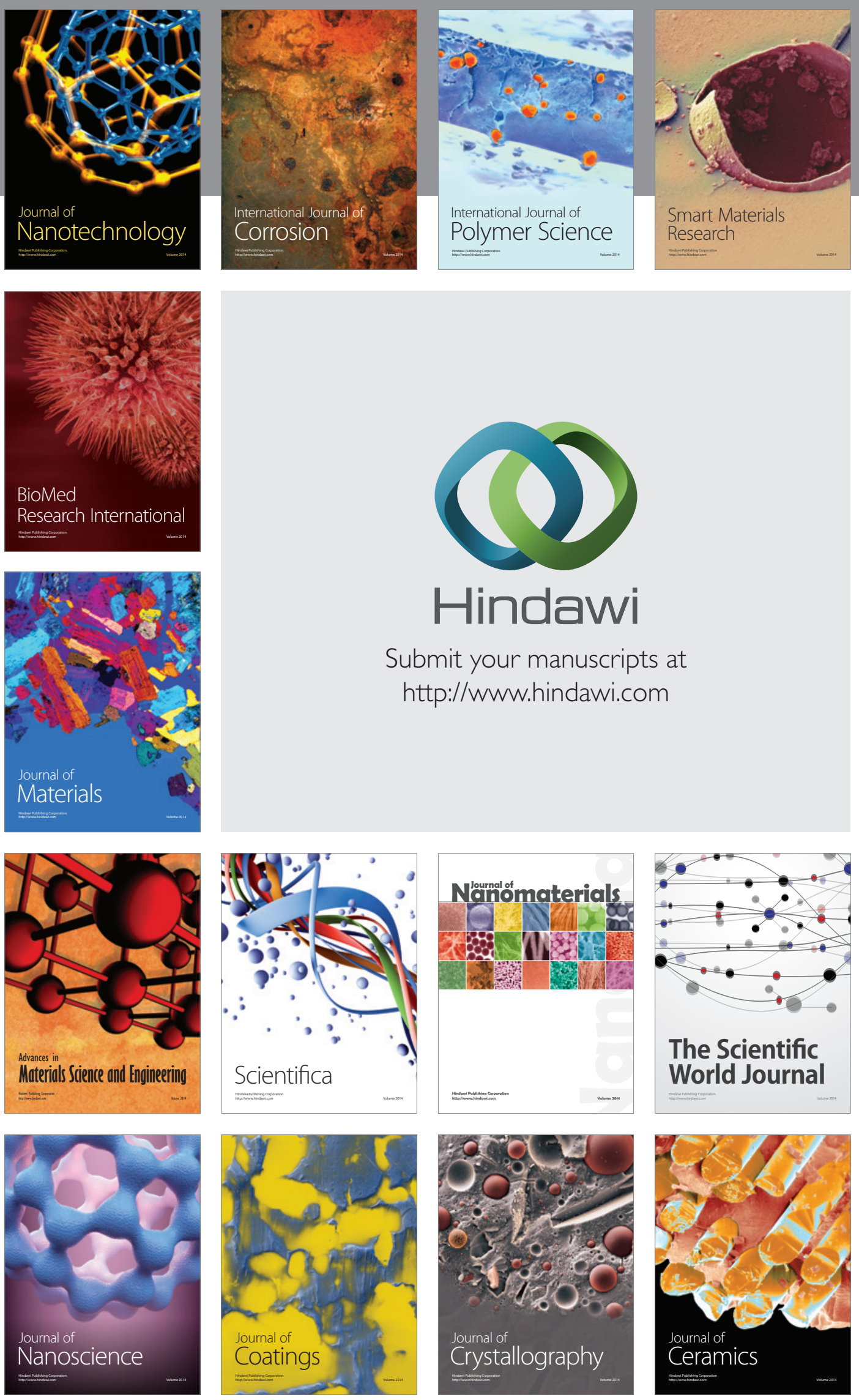

The Scientific World Journal

Submit your manuscripts at

http://www.hindawi.com

\section{World Journal}

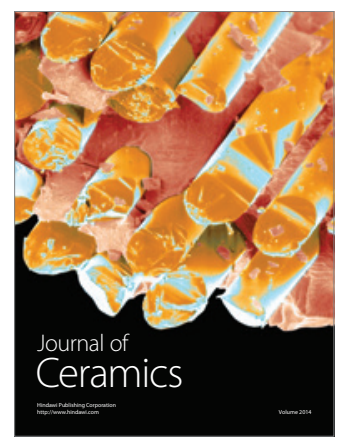

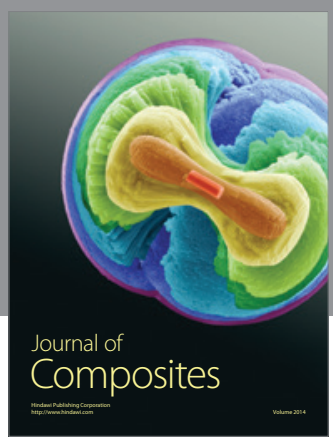
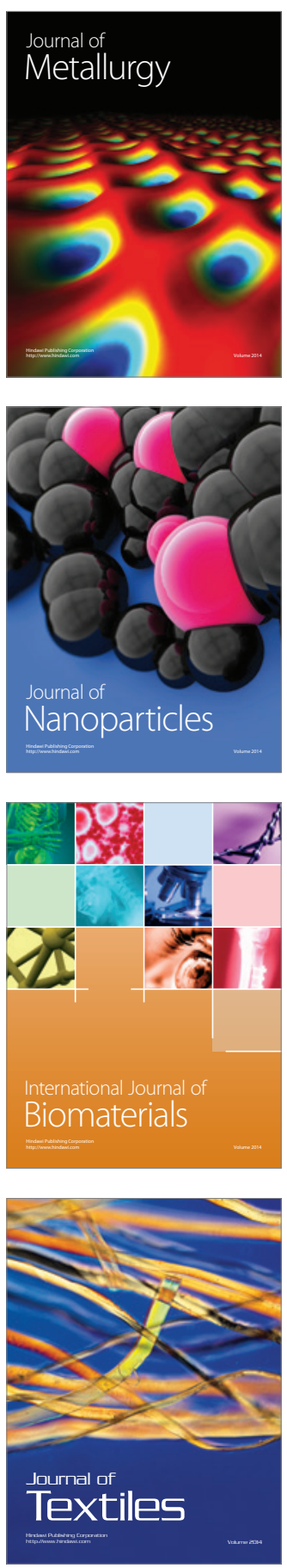